\title{
Investigating the effect of local addition of hydrogen to acoustically excited ethylene and methane flames
}

\author{
Taaha Hussain, Midhat Talibi*, Ramanarayanan Balachandran \\ Department of Mechanical Engineering, University College London, Torrington Place, London WC1E \\ 7JE, United Kingdom
}

\begin{abstract}
While lean combustion in gas turbines is known to reduce NOx, it makes combustors more prone to thermo-acoustic instabilities, which can lead to deterioration in engine performance. The work presented in this study investigates the effectiveness of secondary injection of hydrogen to imperfectly premixed methane and ethylene flames in reducing heat release oscillations. Both acoustically forced and unforced flames were studied, and simultaneous $\mathrm{OH}$ and $\mathrm{H}$ atom PLIF (planar laser induced fluorescence) was conducted. The tests were carried out on a laboratory scale bluff-body combustor with a central V-shaped bluff body. Two-microphone method was used to estimate velocity perturbations from pressure measurements, flame boundary images were captured using high speed Mie scattering, while global heat release fluctuations were determined from $\mathrm{OH}^{*}$ chemiluminescence.

The results showed that hydrogen addition considerably reduced heat release oscillations for both methane and ethylene flames at all the forcing frequencies tested, with the exception of methane flames forced at $315 \mathrm{~Hz}$, where oscillations increased with hydrogen addition. The addition of hydrogen reduced the extent of flame roll-up for both methane and ethylene flames, however, this reduction was larger for methane flames. NOx exhaust emissions were observed to increase with hydrogen addition for both methane and ethylene flames, with absolute NOx concentrations higher for ethylene flames, due to higher flame temperatures.
\end{abstract}

Keywords: hydrogen addition, $\mathrm{H}$ atom PLIF, OH PLIF, combustion oscillations, flame dynamics, flame describing function

doi: $10.1016 / j . i j h y d e n e .2019 .02 .182$

* Corresponding author. Email address: $\underline{\text { m.talibi@ucl.ac.uk }}$ 


\section{Introduction}

Gas turbine engine manufacturers are developing advanced operational strategies based on lean combustion in order to reduce emissions of nitrous oxides (NOx) [1-5]. However, lean burn operation is highly susceptible to thermo-acoustic oscillations (or combustion instabilities), caused by complex interactions between the flow field, acoustics and heat release fluctuations within the combustion chamber [6-9]. The occurrence of these oscillations is problematic as it can result in severe vibrations of the combustor, excessive heat transfer and thermal stresses to the chamber walls, and flame blow-off or flashback [10-13]. This leads to undesirable noise levels, deterioration in engine performance and even complete engine failure. Consequently, extensive research has been carried out to understand the processes responsible for the excitation of these instabilities, however their prediction and control has proven to be a great challenge.

There are many well-researched mechanisms that can lead to heat release oscillations in lean premixed flames, such as, local variations in equivalence ratio, flame sensitivity to pressure/velocity oscillations, and the formation and shedding of vortices [14]. These mechanisms can cause combustion oscillations to grow in amplitude through positive feedback until a self-sustaining limit-cycle amplitude is reached. Combustion instabilities in practical devices are usually suppressed by controlling one or more of the mechanisms mentioned above. Such control measures, taken in order to alter the positive coupling between heat release and pressure/velocity perturbations, and hence suppress or eliminate the combustion instabilities, are generally classified either as passive or active control techniques [7]. Passive control methods involve changes in the hardware that alter the feedback between pressure/velocity fluctuations and the heat release or change the resonant characteristics of the system $[15,16]$, while active measures provide a facility to control the instability dynamically. One of the common methods of active control is to alter the heat release from the flame by secondary fuel injection (or pilot injection), which is the introduction of fuel near the base of the flame. This changes the local air-fuel stoichiometry and leads to a disruption of the phase relation between the heat release modulation and the acoustic pressure (i.e. altering the Rayleigh criteria). Several experimental [14,17,26,18-25] and computational $[19,26-28]$ studies have been conducted to investigate the effectiveness of injecting a proportion of the primary fuel near the base of the flame (that is, pilot injection) on reducing combustion instabilities. In the work presented by Emiris and Whitelaw [17], it was observed that the pressure oscillations were caused by the local extinction and relight of the flame, which occurred due to the high strain rates at the expansion plane which impaired flame stabilisation. The authors were able to reduce the amplitude of the pressure oscillations by rerouting a small proportion of the primary fuel to the secondary injector. In another study Nair and Lieuwen [18], it was noted that the stability of the flame was dependent on flame straining and the strength of the outer recirculation zone. An increase in the flame strain caused the flame to detach from the outer recirculation zones to a location further downstream where it was less stable. It was suggested that the combustion oscillation can be avoided 
by a localised increase in the equivalence ratio in the shear layer. Fuel stratification, that is, local spatial variation in equivalence ratio was recommended to effect this, which would be sufficient to preserve the hot gases in the outer recirculation zones and improve the overall stability. Albrecht et al. [20] observed reductions in thermo-acoustic oscillations and NOx emissions, and hypothesised that this was due to the high momentum created by the secondary fuel injector, which was used to locally introduce fuel and alter the local equivalence ratio.

Due to its higher reaction rates, zero carbon emissions and wider flammability limits, hydrogen $\left(\mathrm{H}_{2}\right)$ is often considered a potential secondary fuel to curtail combustion oscillations. $\mathrm{H}_{2}$ addition increases the lean operation limits, reducing the risk of flame blow-off, and has been observed in previous studies to improve flame ignitability and stability, as well as reduce pressure and heat release perturbations [14,29-37]. Barbosa et al. [35] investigated the effect of injecting hydrogen in a lean premixed propaneair flame on the combustion oscillations. The authors reported a significant reduction in the amplitude of pressure oscillations but a negligible change in the heat release oscillations, which was attributed to the injected hydrogen decoupling the acoustic and heat release oscillations. Similar findings were observed by El-Ghafour et al. [36] who studied the combustion characteristics of natural gas-hydrogen hybrid fuel, and reported considerable improvements in flame stability and reduction in flame length, particularly at high hydrogen addition levels ( $>30 \%$ by volume). Schefer et al. [29] also noted that premixed, swirl stabilised premixed flames became shorter and more robust with $\mathrm{H}_{2}$ enrichment, and that the $\mathrm{OH}$ radical concentration increased considerably with moderate $\mathrm{H}_{2}$ addition (with marginal increase with further $\mathrm{H}_{2}$ addition). The authors [29] also carried out computational analysis of the flames, and observed concurring trends, in that the strain resistance of the flame increased with $\mathrm{H}_{2}$ addition. However, some investigations have also reported an increase in combustion oscillations as a result of $\mathrm{H}_{2}$ addition. Wicksall and Agrawal [38] added hydrogen to methane and propane premixed flames, and observed an increase in acoustic oscillations, which they attributed to the higher adiabatic flame temperature as a result of adding $\mathrm{H}_{2}$. Chen [39] conducted computational analysis to study the effect of adding $\mathrm{H}_{2}$ to propagating spherical methane-air flames, and commented that the addition of $\mathrm{H}_{2}$ could potentially destabilise the flame, as a consequence of the increase in laminar flame speed with $\mathrm{H}_{2}$ addition.

Several authors have observed an increase in NOx emissions with the addition of $\mathrm{H}_{2}$ to hydrocarbon flames [31,35,36,40,41]. Choudhuri and Gollahalli [40] reported a significant increase in NOx emissions when $\mathrm{H}_{2}$ was added to turbulent natural gas flames, which they attributed to higher rates of NOx production via the Zeldovich mechanism due to an increase in the flame temperature and radical pool of $\mathrm{H}, \mathrm{OH}$ and $\mathrm{O}$. While multiple studies have reported an increase in $\mathrm{NOx}$ with $\mathrm{H}_{2}$ addition, some investigations have observed significant reductions in NOx with $\mathrm{H}_{2}$ addition. attributed to the $\mathrm{H}_{2}$ combusting at ultra-lean conditions, hence resulting in a decrease in global flame temperature, and consequently NOx production $[38,42,43]$. 
A common approach when investigating combustion instabilities is to study non-linear flame response to pressure oscillations, by determining the flame describing function, $F D F$ (or flame transfer function). The $F D F$ functions are determined by the quantifying the heat release perturbations with respect to input pressure/velocity perturbations. In practical devices, these pressure perturbations cause unsteady changes in the velocity and equivalence ratio at the inlet of the combustor. While the acoustic response to these instabilities is typically linear, the flame's heat release response can be highly non-linear, particularly at high forcing amplitudes, and hence the overall device can be expected to behave like a coupled non-linear dynamical system [6,44]. Several experimental and numerical investigations have been conducted to determine the FDF [24,25,44-51]. Lieuwen [45] investigated the response of premixed flames to inlet velocity oscillations, and observed that, as flow perturbations increased, the amplitude of the flame response was lower than that predicted by the linear transfer function. Dowling [46] reported that linearization in the flame transfer function is not valid when the magnitude of the amplitude of the velocity perturbations becomes similar to its mean value. Balachandran et al. [44] acoustically forced turbulent bluff-body stabilised flames, and observed that the heat release response first became non-linear for $160 \mathrm{~Hz}$ forcing, when the amplitude of the inlet velocity oscillations was around $15 \%$ of the bulk velocity, with further non-linearities observed at higher forcing amplitudes. The authors attributed this to the inlet perturbations inducing roll up of flame shear layers, and even causing larger-scale flame-annihilation. Many of the key mechanisms related to combustion dynamics (flame annihilation, flame-vortex interaction, fluctuating reaction rate due to mixture fraction variation, modulation in heat transfer) were studied at atmospheric conditions, but were found to be relevant to practical GT operating conditions $[6,52,53]$.

While the utilisation of $\mathrm{H}_{2}$ does have a lot of potential for the development of advanced ultra-low emission combustion strategies, it can be observed that the effect of $\mathrm{H}_{2}$ on both combustion oscillations and on NOx emissions is not very well understood, with often contradictory outcomes, as evidenced in literature. Hence, the focus of the current study, was to understand the effectiveness of the local addition of hydrogen on acoustically forced ethylene and methane premixed flames on flame response and flame shape through a systematic experimental approach. In addition, simultaneous planar laser induced fluorescence (PLIF) of hydroxyl radical $(\mathrm{OH})$ and atomic hydrogen $(\mathrm{H})$ was conducted to observe the effect of $\mathrm{H}_{2}$ addition on flame structure and dynamics. Furthermore, the global heat release oscillation (that is, the total heat release) and the non-linear flame describing function was determined for all test conditions in order to quantify the flame response at different acoustic frequencies. The authors believe that this is the first study of its kind whereby secondary fuel injection of $\mathrm{H}_{2}$ is being employed on imperfectly premixed flames, which simulate operational conditions relevant to practical combustors. 


\section{Experimental methodology}

\subsection{Burner}

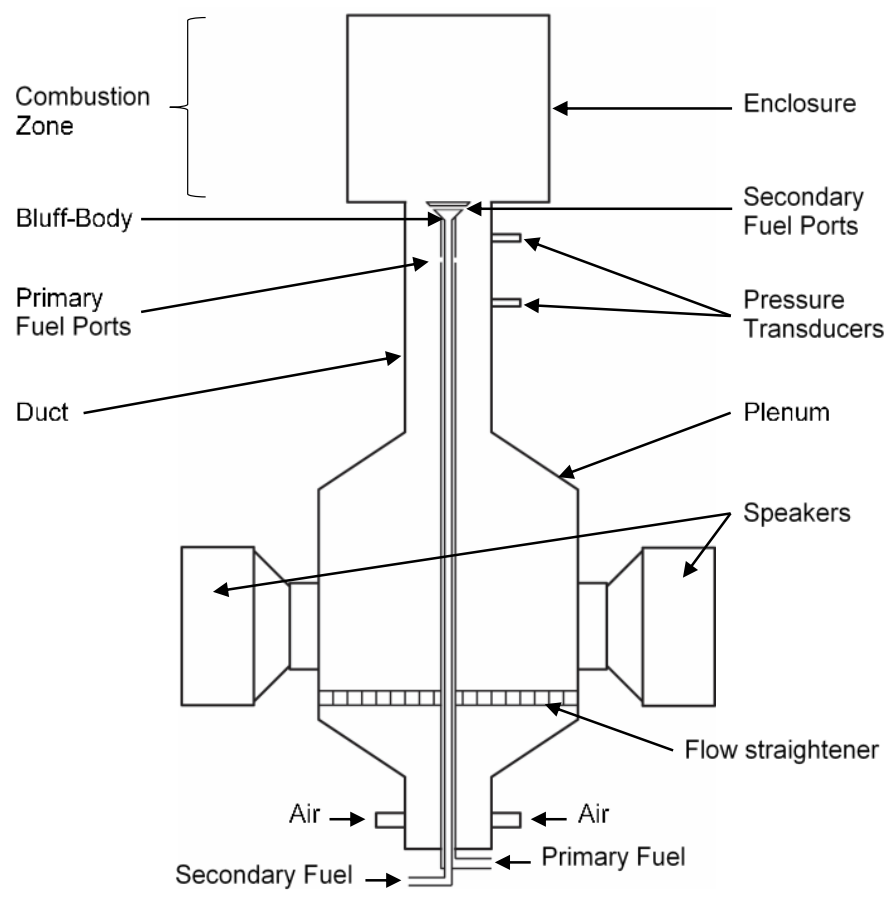

(a)

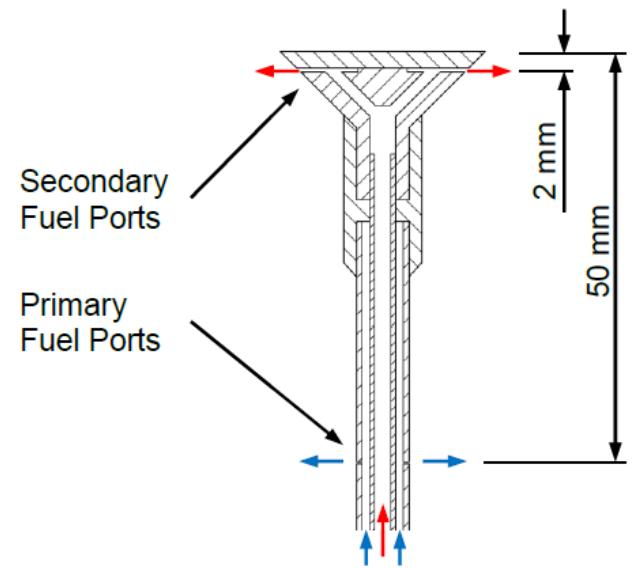

(b)

Figure 1 (not drawn to scale): (a) Schematic of the combustor assembly. (b) Sectional view of the bluffbody, showing the primary and secondary fuel ports.

An acoustically excited bluff body stabilised combustor, based on the design by Balachandran et al. [44], was used in this study. The schematic of the combustor is shown in Fig. 1a. The plenum had an internal diameter (ID) of $100 \mathrm{~mm}$ and a length of $200 \mathrm{~mm}$, with divergent and convergent cross sections at the inlet and exit of the plenum which prevented any flow separation during the expansion and contraction of the gas. The flow was streamlined using a section of honeycomb mesh placed at the entrance of the plenum. Four orthogonally placed speakers, rated at $60 \mathrm{~W}$ each, were mounted circumferentially on the plenum at a distance of $100 \mathrm{~mm}$ from the plenum inlet, to impose inlet velocity fluctuations. A TTi $60 \mathrm{MHz}$ waveform generator was used to generate sinusoidal signals, which were first amplified before being supplied to the speakers. The flame was acoustically forced at different frequencies which corresponded to the geometric resonant frequencies (detailed in Section 2.3) of the burner assembly. In addition, the peak-to-peak voltage of the waveform, that is, the magnitude of forcing, was also varied. Experiments in which such velocity fluctuations were generated will be referred to as 'forced' conditions, while the cases where the speakers were switched off will be the 'unforced' conditions. The duct above the plenum had an ID of $35 \mathrm{~mm}$, and provisions for mounting two high-sensitivity pressure transducers (KuLite model XCS-093, sensitivity 4.2857x10-3 mV/Pa) which were used to measure pressure fluctuations and characterise the acoustic response of the burner. 
The signal from the transducers was amplified using a Flyde Micro Analogue amplifier and acquired on a PC using National Instruments data acquisition systems. The two-microphone method was employed to estimate velocity fluctuations.

The bluff body was used to stabilise the flame, and was conical in shape (Fig. 1b), with a diameter of $25 \mathrm{~mm}$, resulting in a blockage ratio of $\sim 50 \%$. The flame is primarily anchored at the inner shear layer, with some flame elements at the outer shear layer (as can be observed in Fig.3 later). The principle of flame stabilisation in this work is the same as that presented in Balachandran et al [44]. Six primary fuel ports (each of diameter $0.25 \mathrm{~mm}$ ) were placed circumferentially on the main fuel pipe, $50 \mathrm{~mm}$ below the exist of the burner. In addition, the bluff body also had a $2 \mathrm{~mm}$ wide circumferential passage located $2 \mathrm{~mm}$ below the burner exit that enabled secondary injection of fuel or diluent gas. Two long concentric tubes were welded to the bluff body which served as fuel supply lines for the two injection ports. Two different types combustion modes could be achieved using this bluff body burner. The fuel could either be mixed completely with the air before entering the combustor to achieve a "fully premixed' flame, or the fuel could be locally introduced through the primary fuel ports (Fig. 1b) at choking conditions resulting in a partially premixed mixture thereby producing an imperfectly premixed' flame - flame with a spatial variation in premixedness. These flames are also known as 'technically premixed' or 'industrial premixed'. Acoustic excitation additionally introduces temporal variation in equivalence ratio. This temporal variation is the most important phenomenon in technically/imperfectly premixed forced flames, and can be simply modelled as outlined in Semlitsch, et. al. [54] for a burner configuration similar to this study.

The secondary fuel ports allowed local addition of gases with either of the above combustion modes. In this study, only imperfectly premixed flames have been used for relevance to practical combustors. The combustion zone of the combustor was enclosed using a UV fused silica quartz cylinder of ID 70 $\mathrm{mm}$ and length $100 \mathrm{~mm}$. The quartz enclosure prevented local equivalence ratio fluctuations due to air entrainment from the surroundings.

The air was supplied from a central compressor while the fuel and diluent gases were supplied from compressed gas cylinders. The flow rates of the fuel, air and diluent gases were controlled using digital mass flow meters (Red-Y Smart), which had an accuracy of $\pm 1.5 \%$ of the full-scale reading. 


\subsection{Optical diagnostic arrangement}

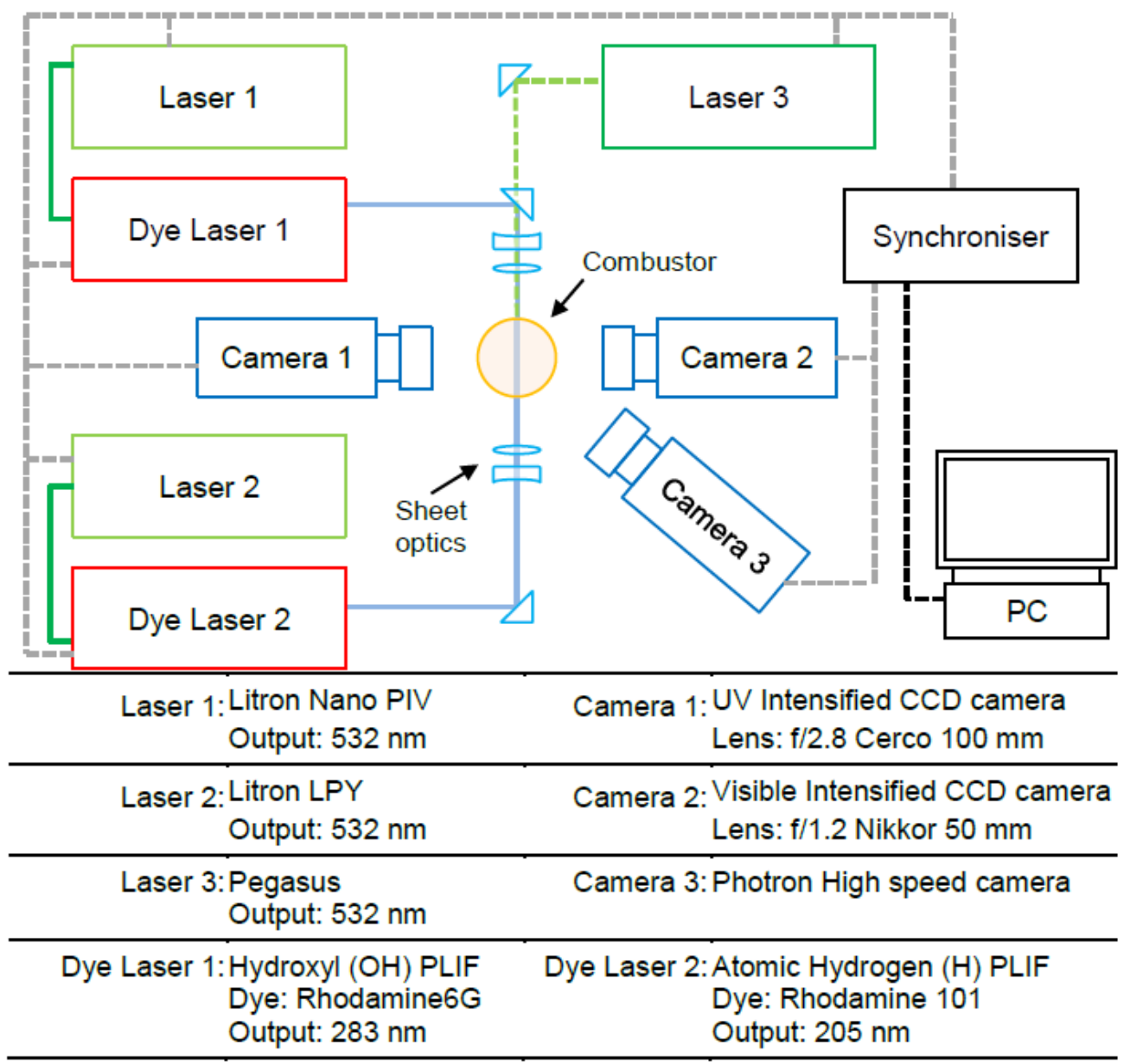

Figure 2: Optical system setup

Figure 2 shows the layout of the optical diagnostic facility used for planar laser induced fluorescence (PLIF) imaging and high-speed flame imaging. For hydroxyl radical (OH) PLIF, a combination of Nd:YAG pump laser (Laser 1) and tuneable dye laser containing Rhodamine $6 \mathrm{G}$ dye and a frequency doubler (Dye laser 1) was used to generate a beam of around $283 \mathrm{~nm}$ to pump the Q1 (6.5) transition of the $\mathrm{A}^{1} \Sigma-\mathrm{X}^{2} \Pi(1,0)$ band of $\mathrm{OH}$. This excitation wavelength was selected as the fluorescence is less susceptible to changes in pressure and temperature. The beam was converted into a thin sheet of height $50 \mathrm{~mm}$ (and laser sheet thickness of $\sim 200 \mu \mathrm{m}$ ), using a combination of a plano-concave and a biconvex lens. The $\mathrm{OH}$ fluoresced at a wavelength of approximately $310 \mathrm{~nm}$, and was captured using a UVintensified CCD camera (Camera 1) fitted with the $100 \mathrm{~mm} \mathrm{f} / 2.8$ Cerco lens and a combination of UG 11 and WG 305 filters, to allow light of appropriate wavelengths through to the camera. To image atomic hydrogen (H) PLIF, a similar system of a pump (Laser 2) and a tuneable dye laser (Dye laser 2) was used; the dye laser contained Rhodamine 101 dye, and was fitted with frequency doubler and tripler crystals, which produced a beam of $205.1 \mathrm{~nm}$ needed to excite $\mathrm{H}$ in the flame. Similar to the OH setup, plano-convex optics combination was used to expand the beam into a collimated light sheet of height 
$7.5 \mathrm{~mm}$ for H PLIF. The $\mathrm{H}$ fluoresced at $656 \mathrm{~nm}$, which was captured on Camera 2 which was coupled with a visible intensifier fitted with a f/1.2 $50 \mathrm{~mm}$ Nikkor lens and an interference filter of centre wavelength $656 \mathrm{~nm}$. The exposure was set to a short time interval of $0.3 \mu$ s to reduce interference from the natural chemiluminescence of the flame. High speed planer laser Mie-scattering (at $3000 \mathrm{~Hz}$ ) of olive oil droplets in reactant mixtures was carried out using a Pegasus $532 \mathrm{~nm}$ output laser and a Photron high speed camera (Camera 3, Fig. 2). These high-speed images were used to identify the boundary between the reactants and combustion products. $\mathrm{OH}^{*}$ chemiluminescence was measured using a photomultiplier tube (PMT). The PMT was fitted with a convex lens which focused the entire flame on the PMT collection window. An interference filter with a centre wavelength of $307 \mathrm{~nm}$ and bandpass of $\pm 10 \mathrm{~nm}$ was mounted on the PMT to detect $\mathrm{OH}^{*}$ chemiluminescence.

In addition, the concentrations of carbon dioxide $\left(\mathrm{CO}_{2}\right)$ and nitrogen oxides $(\mathrm{NOx})$ in the burner exhaust gas were measured using the Horiba MEXA 9100HEGR exhaust gas analyser rack. The rack was fitted with a non-dispersive infrared absorption detector for $\mathrm{CO}_{2}$ measurements, and a chemiluminescence analyser for NOx detection. The samples were collected $120 \mathrm{~mm}$ downstream of the burner bluff body and were filtered for particulates before being supplied to the analyser. 


\subsection{Flow conditions}

\begin{tabular}{|c|c|c|c|c|c|c|c|c|}
\hline \multirow[b]{2}{*}{ Label } & \multirow[b]{2}{*}{$\begin{array}{c}\text { Air } \\
\text { (slpm) }\end{array}$} & \multicolumn{2}{|c|}{ Primary } & \multicolumn{2}{|c|}{ Secondary } & \multirow[b]{2}{*}{$\phi_{\text {Global }}$} & \multirow[b]{2}{*}{$S_{L}(\mathrm{~cm} / \mathrm{s})$} & \multirow[b]{2}{*}{$T_{a d}(\mathrm{~K})$} \\
\hline & & $\begin{array}{l}\mathrm{C}_{2} \mathrm{H}_{4} \\
\text { (slpm) }\end{array}$ & $\begin{array}{c}\mathrm{C}_{2} \mathrm{H}_{4} \\
\%\end{array}$ & $\begin{array}{c}\mathrm{H}_{2} \\
\text { (slpm) }\end{array}$ & $\begin{array}{l}\mathrm{H}_{2} \\
\%\end{array}$ & & & \\
\hline $0 \% \mathrm{H}_{2}$ & 250.0 & 14.2 & 100.0 & 0.0 & 0.0 & 0.81 & 53.5 & 2180 \\
\hline $5 \% \mathrm{H}_{2}$ & 250.0 & 14.1 & 95.0 & 0.7 & 5.0 & 0.81 & 54.2 & 2184 \\
\hline $10 \% \mathrm{H}_{2}$ & 250.0 & 13.9 & 90.0 & 1.5 & 10.0 & 0.81 & 54.9 & 2176 \\
\hline $20 \% \mathrm{H}_{2}$ & 250.0 & 13.6 & 80.0 & 3.4 & 20.0 & 0.81 & 56.5 & 2177 \\
\hline $30 \% \mathrm{H}_{2}$ & 250.0 & 13.2 & 70.0 & 5.7 & 30.0 & 0.81 & 58.5 & 2176 \\
\hline
\end{tabular}

(a)

\begin{tabular}{|c|c|c|c|c|c|c|c|c|}
\hline \multirow[b]{2}{*}{ Label } & \multirow[b]{2}{*}{$\begin{array}{c}\text { Air } \\
\text { (slpm) }\end{array}$} & \multicolumn{2}{|c|}{ Primary } & \multicolumn{2}{|c|}{ Secondary } & \multirow[b]{2}{*}{$\phi_{\text {Global }}$} & \multirow[b]{2}{*}{$S_{L}(\mathrm{~cm} / \mathrm{s})$} & \multirow[b]{2}{*}{$T_{a d}(\mathrm{~K})$} \\
\hline & & $\begin{array}{c}\mathrm{CH}_{4} \\
\text { (slpm) }\end{array}$ & $\begin{array}{c}\mathrm{CH}_{4} \\
\%\end{array}$ & $\begin{array}{c}\mathrm{H}_{2} \\
\text { (slpm) }\end{array}$ & $\begin{array}{l}\mathrm{H}_{2} \\
\%\end{array}$ & & & \\
\hline $0 \% \mathrm{H}_{2}$ & 250.0 & 18.2 & 100.0 & 0.0 & 0.0 & 0.70 & 21.2 & 1827 \\
\hline $5 \% \mathrm{H}_{2}$ & 250.0 & 18.1 & 95.0 & 1.0 & 5.0 & 0.70 & 22.2 & 1839 \\
\hline $10 \% \mathrm{H}_{2}$ & 250.0 & 17.8 & 90.0 & 2.0 & 10.0 & 0.70 & 23.3 & 1839 \\
\hline $20 \% \mathrm{H}_{2}$ & 250.0 & 17.1 & 80.0 & 4.3 & 20.0 & 0.69 & 25.3 & 1837 \\
\hline $30 \% \mathrm{H}_{2}$ & 250.0 & 16.3 & 70.0 & 7.0 & 30.0 & 0.69 & 27.7 & 1836 \\
\hline
\end{tabular}

(b)

Table 1: Experimental flow conditions for the local addition of hydrogen to (a) imperfectly premixed ethylene flames, and (b) imperfectly premixed methane flames.

Table 1 shows the flow conditions used for the local addition of hydrogen $\left(\mathrm{H}_{2}\right)$ to imperfectly premixed ethylene and methane flames. The ethylene equivalence ratio was selected as it also allowed selfexcitation of ethylene flames (with modified combustor length. Note: self-excited results have not been presented in this paper). For the methane tests, the equivalence ratio had to be reduced as the measurement capability of the flowmeter did not allow higher flowrates. $\mathrm{H}_{2}$ was supplied through the secondary fuel ports in the bluff body, as described in Section 2.1, and was increased in steps, measured as a percentage of the total volume flow rate of the mixture. The volume flow rate of air was kept constant to keep the changes in the flow turbulence negligible (about $1.8 \%$ total flow rate change at maximum $\mathrm{H}_{2}$ addition) at the entrance of the combustion zone with small increments in the fuel quantities. The overall laminar flame speed of the fuel mixture, $S_{L}$, was calculated using COSILAB [55]. The flame speed values do not represent local flame speeds, but show that the addition of $\mathrm{H}_{2}$ generally increases the overall laminar flame speed. It should be noted that the COSILAB calculations assume the mixture to be fully premixed, but for the study described in this work, the hydrogen was not premixed with either the air or the primary fuel. In the case of ethylene/hydrogen mixtures, $S_{L}$ increased 
by $10 \%$ when the proportion of $\mathrm{H}_{2}$ was increased from $0 \%$ to $30 \%$, while, in the case of methane/hydrogen mixtures $S_{L}$ increased by $30 \%$ for the same increase in $\mathrm{H}_{2}$.

For the forced conditions, preliminary tests were conducted whereby the air flow rate was set to 250 $\mathrm{lpm}$, and the frequency varied from 20 to $450 \mathrm{~Hz}$ in steps of $10 \mathrm{~Hz}$. The maximum velocity perturbations occurred at frequencies of 30, 255 and $315 \mathrm{~Hz}$, and hence the flames were studied under these three forcing frequencies. The global equivalence ratio $\left(\phi_{\text {Global }}\right)$, presented in Table 1 is calculated from input fuel and air flowrates without taking into account the premixedness of the fuel-air mixture at the inlet of the combustor, and/or any variation in the equivalence ratio caused by acoustic forcing.

\section{Data Analysis}

\subsection{Global heat release fluctuation}

The pressure transducer signals were analysed using the two-microphone technique to calculate the velocity fluctuation, $u^{\prime}$, and normalised by bulk velocity $\langle U\rangle$, at the inlet to the combustion chamber [44,56]. Numerous studies have used $\mathrm{OH}^{*}$ to investigate combustion dynamics [44,57-60]. Furthermore, Balachandran, et. al. [44] experimentally compared $\mathrm{OH}^{*}$ with other heat release measurement techniques (flame surface density-FSD, simultaneous $\mathrm{OH}-\mathrm{CH}_{2} \mathrm{O}$ planar heat release technique) and concluded that $\mathrm{OH}^{*}$ is suitable to represent heat release. Kim and Park [61] have discussed the relationship between $\mathrm{OH}^{*}$ and heat release, in the context of hydrogen addition. Their work clearly shows that the relationship between $\mathrm{OH}^{*}$ intensity and total heat release is linear when hydrogen is added. Hence, in this study involving hydrogen addition in hydrocarbon flames, $\mathrm{OH}^{*}$ can be employed for investigating heat release modulation with confidence.

As expected, it was observed in this work that the $\mathrm{OH}^{*}$ chemiluminescence signal had a cyclic response under acoustic forcing. The spectral time traces of $\mathrm{OH}^{*}$ were analysed using the Fast Fourier Transform (FFT) technique to evaluate the complex amplitude of $O H^{* \prime}$ (half peak-to-peak value), at the forcing frequency, $f$. This value was normalised with the time averaged mean $\left\langle O H^{*}\right\rangle$ to obtain $O H^{* \prime}(f) /\left\langle O H^{*}\right\rangle$. These normalised values were used to represent the heat release fluctuation, $Q^{\prime}(f) /\langle Q\rangle$. The flame describing function, $F D F$, (also known as the non-linear flame transfer function, $N F T F$ ) was determined from the ratio of the heat release fluctuations and the velocity perturbations, $F D F=\left(Q^{\prime}(f) /\langle Q\rangle\right) /($ $\left.u^{\prime} /\langle U\rangle\right)$.

\subsection{Image processing}

The raw images of $\mathrm{OH}$ and $\mathrm{H}$ PLIF (captured using camera 1 and 2, respectively, as shown in Fig. 2) were corrected for background noise mainly generated due to the scatter of laser light in the room and 
reflection of the laser light on the quartz cylinder. Beam profile correction was then carried out on the images to correct for any spatial in-homogeneities in the beam energy profile. The images were additionally corrected for shot-to-shot variation by using two photodiodes that measured changes in laser energy during PLIF imaging. For each experimental condition, one hundred images were used to generate an averaged image. Preliminary analysis done to determine the effect of the number of images averaged showed that the cumulative average of the flame surface area fluctuated during the first 20 images but then levelled out.

To obtain the flame front, the averaged OH PLIF images were first converted into binarised images of black and white regions, with the black regions showing the burnt gas; this was based on algorithms defined in Otsu's method [62]. The binarised images were then put through a boundary trace function to produce an image of a single pixel thick flame front. Figure 3 a gives a pictorial representation of the processing steps involved. The averaged flame front images were revolved around the central axis to obtaine a 3-dimensional contour of the flame (not shown in Fig.3), which was then multiplied by the resolution $(55 \mu \mathrm{m} / \mathrm{pixel})$ to determine the flame length, here used to represent the vertical cross-section of the flame surface area $(F S)$. The normalised flame surface, $F S^{\prime} /\langle F S\rangle$, was obtained by determining the ratio between the amplitude of the flame surface area fluctuation (at the forcing frequency, $f$ ) and the mean flame surface area, $\langle F S\rangle$. Only the left-hand side of the flame was used (as the flame was axisymmetric), which was further divided into three regions, and the total flame surface area in each of these regions was summed up. Region A ( $2.5 \mathrm{~mm}$ to $15 \mathrm{~mm}$ from the base) and Region B ( $25 \mathrm{~mm}$ to $40 \mathrm{~mm}$ from the base) were used to determine the flame surface area of the initial and developed size of the flame roll-up, and how this changed with hydrogen addition. Region C (2.5 mm to $45 \mathrm{~mm}$ from the base) considered the entire imaged region which gave an overall view of the changes brought about with the introduction of hydrogen. Figure $3 \mathrm{~b}$ shows the regions $\mathrm{A}, \mathrm{B}$ and $\mathrm{C}$ on a flame front. 

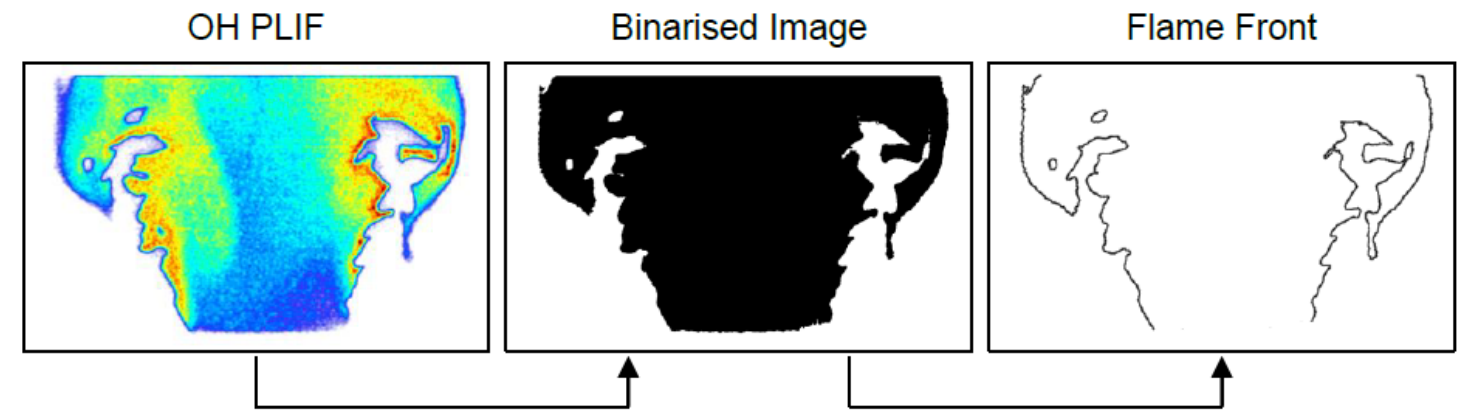

(a)

Binarisation

Boundary Trace

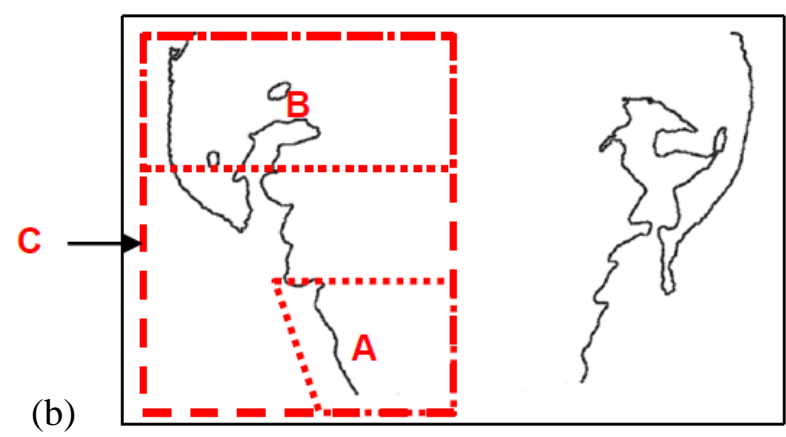

Figure 3: (a) Order of processing steps involved to detect the flame front from an OH PLIF image, and (b) Regions A, B and C on a flame front image 


\section{Results and discussion}

\subsection{Unforced ethylene-hydrogen and methane-hydrogen flames}

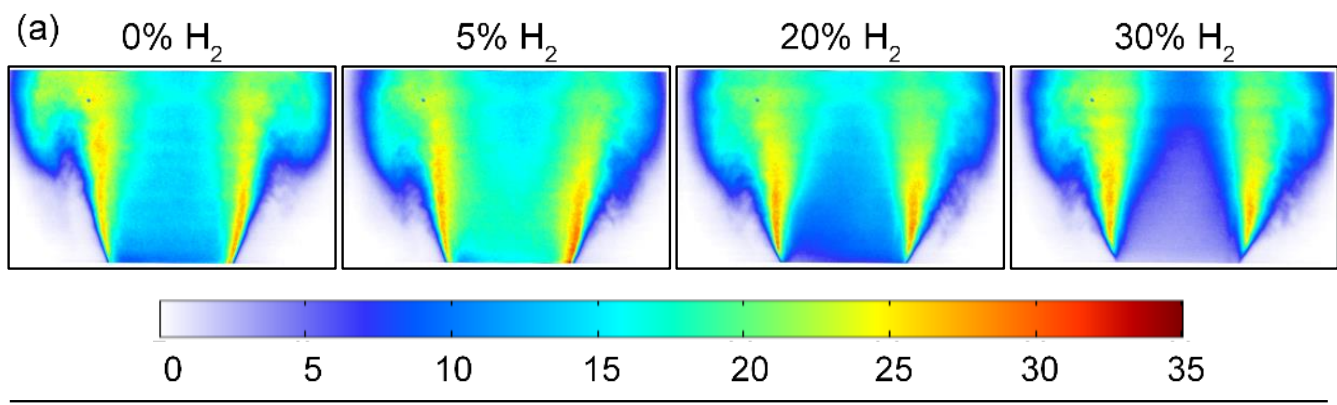

(b)

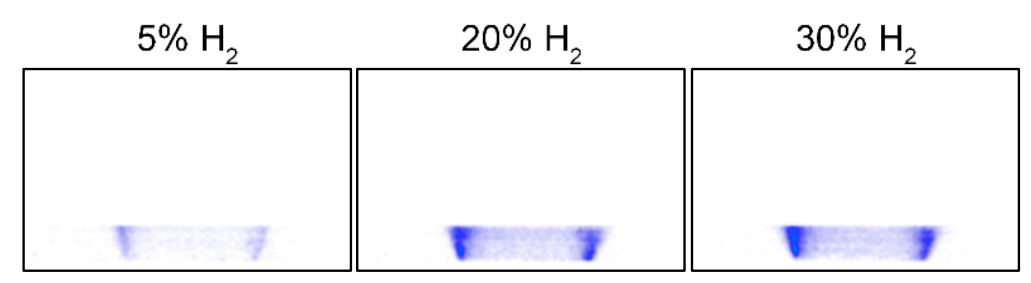

\begin{tabular}{lllllll}
\hline & & & & & & 1 \\
& 2 & 4 & 6 & 8 & 10 \\
\hline
\end{tabular}

\begin{tabular}{|l|l|l|l|l|}
\hline (c) $0 \% \mathrm{H}_{2}$ & $5 \% \mathrm{H}_{2}$ & $20 \% \mathrm{H}_{2}$ & $30 \% \mathrm{H}_{2}$ \\
\hline & & & & \\
& & & & \\
\hline
\end{tabular}

Figure 4: Averaged (a) OH PLIF, (b) H PLIF, and (c) flame front images for the unforced, imperfectly premixed ethylene flames with varying quantities of hydrogen addition

Figure 4 shows the averaged OH PLIF, H PLIF and flame front images for unforced, imperfectly premixed ethylene flames with different levels of hydrogen addition. From the OH PLIF images it can be seen that, as the percentage $\mathrm{H}_{2}$ was increased, the intensity of the $\mathrm{OH}$ fluorescence signal increased at the inner shear layers, but decreased at the central recirculation zone. The increase in signal intensity at the shear layers could indicate higher reaction rates. The reaction, $\mathrm{H}+\mathrm{O}_{2}=\mathrm{OH}+\mathrm{O}$, has been shown to be a dominant consumer of atomic hydrogen and a key chain-branching reaction producing $\mathrm{OH}$ radicals. Hence, an increase in $\mathrm{H}_{2}$ could increase the concentration of $\mathrm{OH}$ radicals at the flame front, hence promoting higher reaction rates. The reduction in the $\mathrm{OH}$ signal intensity at the central recirculation zone could potentially be attributed to alterations in size, position or temperature of the zone. However, these cannot be confirmed within the scope of the current experimental setup. The $\mathrm{H}$ PLIF images in Fig. $4 \mathrm{~b}$ show a considerable increase in the intensity of the signal at the lower inner shear layers with increase in $\mathrm{H}_{2}$. The increase in signal intensity demonstrates that the $\mathrm{H}_{2}$ fuel broke down immediately into atomic $\mathrm{H}$ as it was introduced in the combustion zone. Hence, the local addition 
of $\mathrm{H}_{2}$ resulted in an increase in the equivalence ratio (locally) at the base of the flame. The averaged flame front images (Fig. 4c) show non-linear changes in the height and width of the flame with increasing $\mathrm{H}_{2}$. As an example, at a height of $5 \mathrm{~mm}$ above the burner exit, the flame diameter increased from $30 \mathrm{~mm}$ to $31 \mathrm{~mm}$ when the $\mathrm{H}_{2}$ addition was increased to $20 \%$. However, the diameter did not increase when the $\mathrm{H}_{2}$ addition was further increased to $30 \%$. The flame front images also show the flame brush appear to expand closer to the burner exit with increase in $\mathrm{H}_{2}$ addition.

(a)

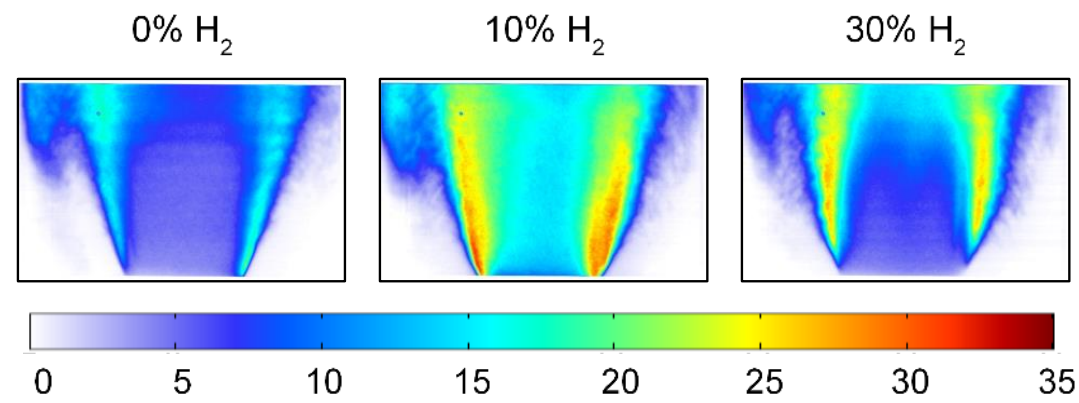

(b)
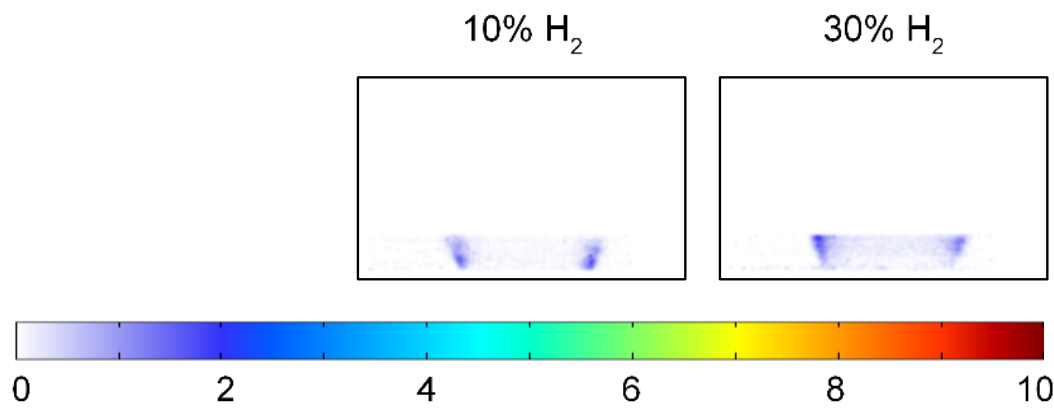

(c)
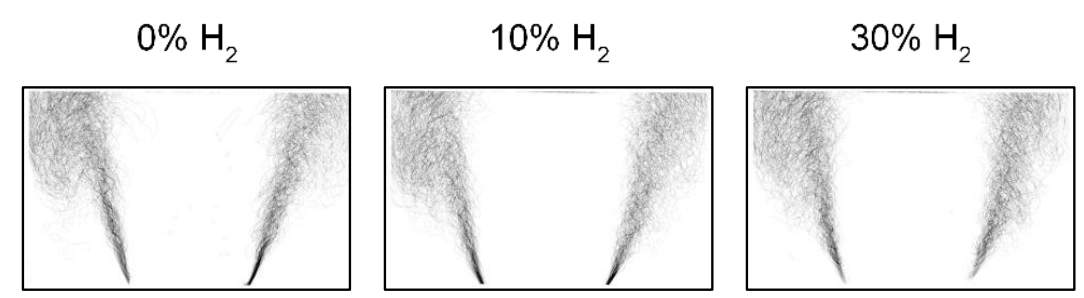

Figure 5: Averaged (a) OH PLIF, (b) H PLIF, and (c) flame front images for the unforced, imperfectly premixed methane flames with varying quantities of hydrogen addition

Figure 5 shows the averaged OH PLIF, H PLIF and flame front images for unforced, imperfectly premixed methane flames with different levels of hydrogen addition. Similar to the ethylene flames, an increase in $\mathrm{OH}$ intensity can be observed at the flame front with $\mathrm{H}_{2}$ addition for the methane flames (Fig. 5a). However, the $\mathrm{OH}$ fluorescence signal is seen to drop in the central recirculation zone when the $\mathrm{H}_{2}$ addition is increased to $30 \%$. An increase in the atomic H PLIF signal at the base of the flame is observed with increase in $\mathrm{H}_{2}$ addition, attributed to the added $\mathrm{H}_{2}$ breaking down in that region. The flame diameter also increases by 1-2 $\mathrm{mm}$ (a 3-7\% change), with the flame brush starting closer to the burner exit. 


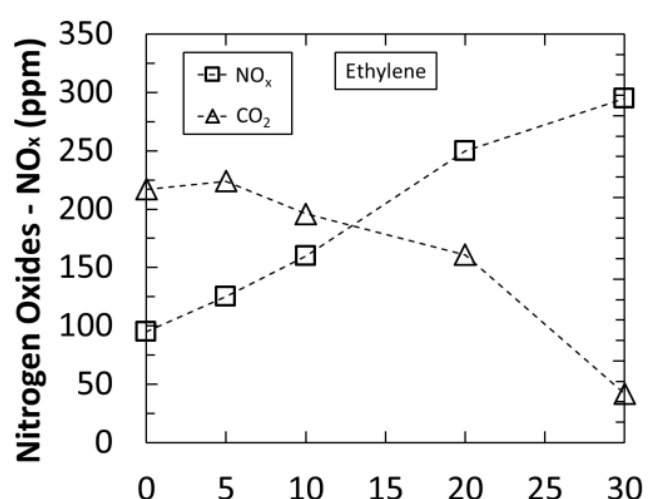

(a)
12

Hydrogen addition (\%)

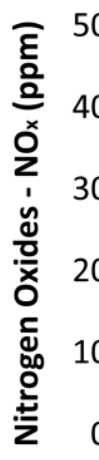

(b)

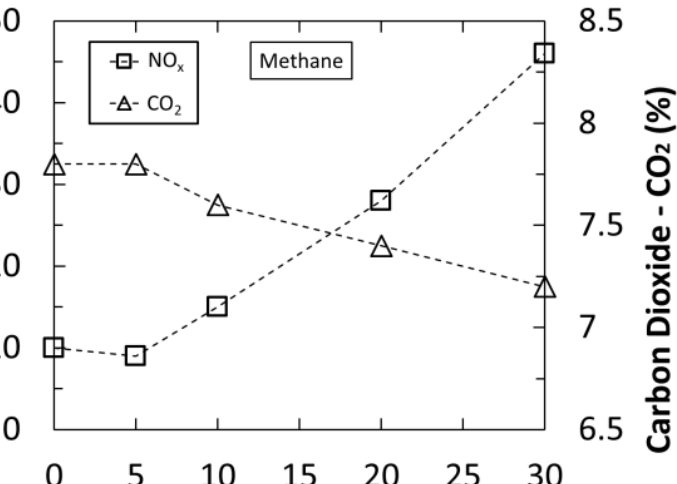

Hydrogen addition (\%)

Figure 6: Change in emissions of nitrogen oxides $(\mathrm{NOx}-\mathrm{ppm})$ and carbon dioxide $\left(\mathrm{CO}_{2}-\%\right)$ with change in \% hydrogen addition for (a) imperfectly premixed ethylene flames and (b) imperfectly and fully premixed methane flames.

Figure 6 shows the change in the exhaust emissions of $\mathrm{NOx}(\mathrm{ppm})$ and $\mathrm{CO}_{2}(\%)$ for different levels of $\mathrm{H}_{2}$ addition. In the case of both ethylene and methane flames, the $\mathrm{CO}_{2}$ dropped by $0.5 \%$ at the maximum level of $\mathrm{H}_{2}$ addition of $30 \%$. This reduction can be attributed to the reduction in the carbon content of the fuel mixture being supplied to the burner (due to ethylene and methane being replaced by $\mathrm{H}_{2}$ ), hence resulting in lower exhaust emissions of $\mathrm{CO}_{2}$. Considering the NOx emissions, it can be seen from Fig. 6 that for the zero $\mathrm{H}_{2}$ addition case, ethylene flames produced significantly higher levels of NOx as compared to methane. This can be expected as the adiabatic flame temperature of ethylene is considerably higher $(2600 \mathrm{~K})$ as compared to that of methane $(2200 \mathrm{~K})$, and NOx emissions have been shown to non-linearly increase with temperature [63,64]. NOx emissions are also seen to increase significantly with $\mathrm{H}_{2}$ addition; for the maximum $\mathrm{H}_{2}$ addition level of $30 \%$, NOx levels increased from $100 \mathrm{ppm}$ to $300 \mathrm{ppm}$ for ethylene flames and from $10 \mathrm{ppm}$ to about $50 \mathrm{ppm}$ for methane flames. The increase in $\mathrm{NOx}$ emissions with $\mathrm{H}_{2}$ addition is also expected, as $\mathrm{H}_{2}$ results in higher flame temperatures, as observed in previous studies [32,35]. It can be seen from the data presented in Table 1 that the variation in flame temperatures for each hydrocarbon flame was minimal (within $\pm 4 \mathrm{~K}$ ). This is because while energy was added through the addition of hydrogen, the flow rate of the hydrocarbon fuel (ethylene or methane) was reduced to maintain a constant overall equivalence ratio. The observed change in NOx is beyond the change in adiabatic flame temperatures. The authors believe this is due to non-uniform temperature distribution in the flame, mainly caused by high levels of stratification within the flame. 
4.2. Forced imperfectly premixed ethylene-hydrogen and methane-hydrogen flames

Global Heat Release Fluctuation
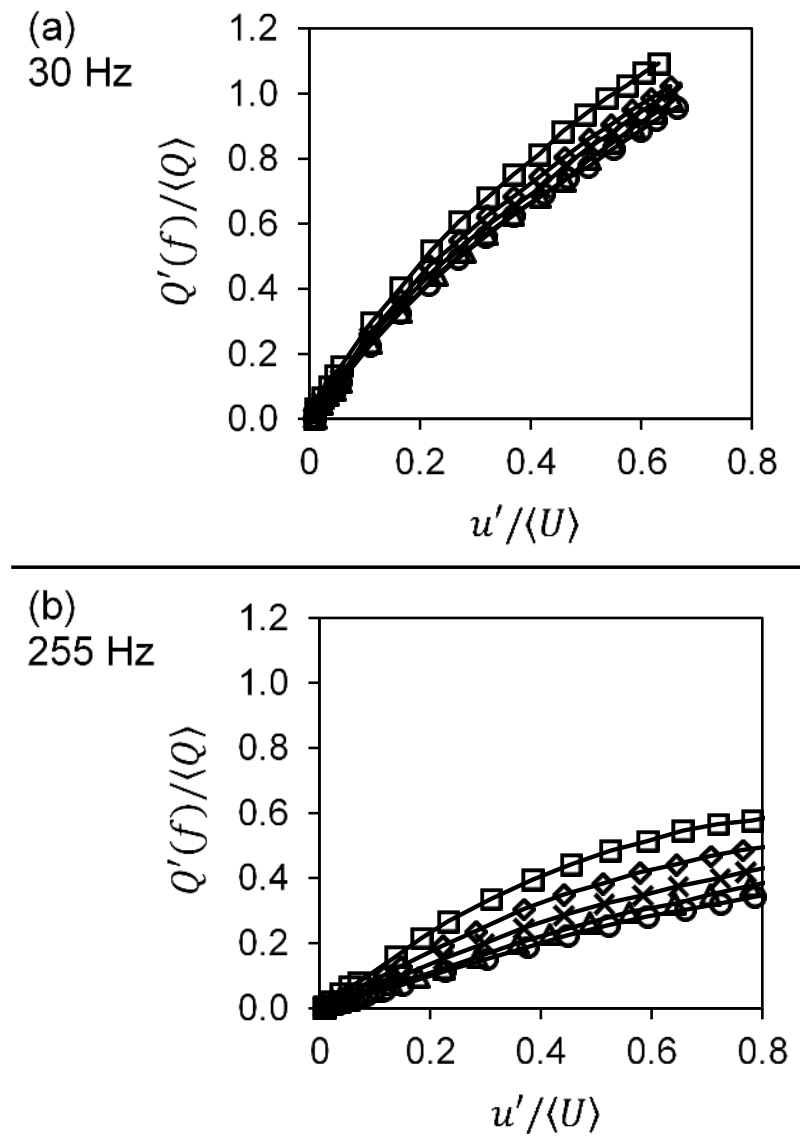

(b) $255 \mathrm{~Hz}$

\section{(c)}

$315 \mathrm{~Hz}$

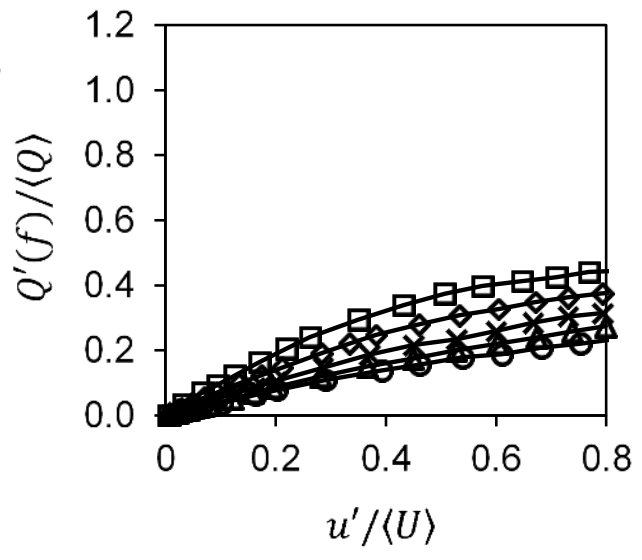

Flame Describing Function

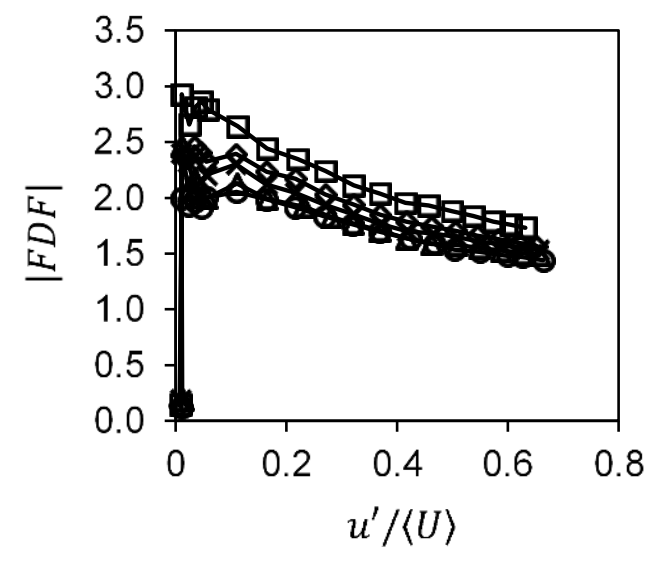

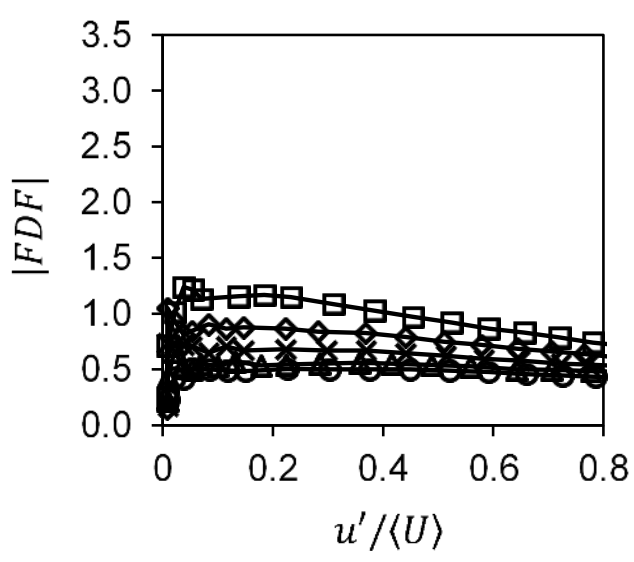

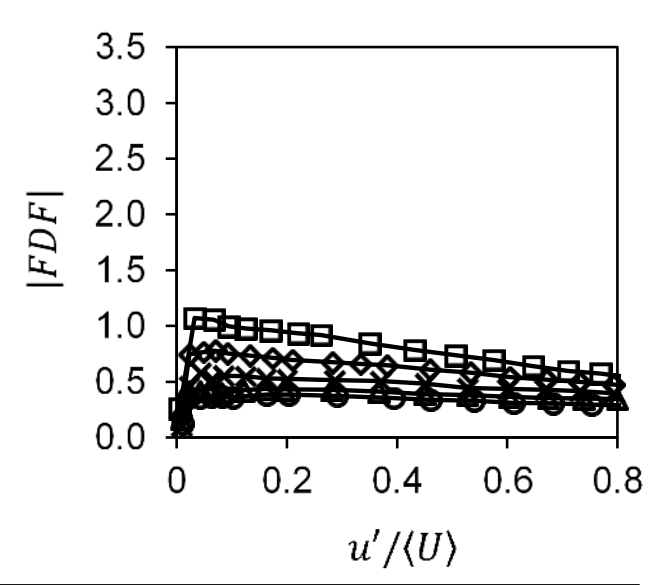

$\square 0 \% \mathrm{H}_{2} \diamond 5 \% \mathrm{H}_{2} \rightarrow 10 \% \mathrm{H}_{2} \triangle 20 \% \mathrm{H}_{2} \multimap-30 \% \mathrm{H}_{2}$

Figure 7: Dependence of the global heat release fluctuation and the magnitude of the flame describing function evaluated from $\mathrm{OH}^{\star}$ chemiluminescence of imperfectly premixed ethylene flames with local addition of hydrogen on velocity fluctuations, at forcing frequencies of (a) $30 \mathrm{~Hz}$, (b) $255 \mathrm{~Hz}$, and (c) $315 \mathrm{~Hz}$. 
(a)

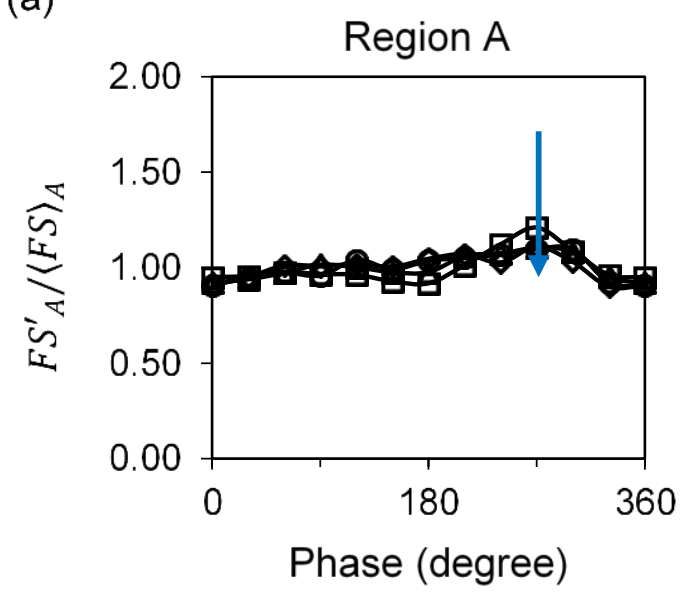

(b)

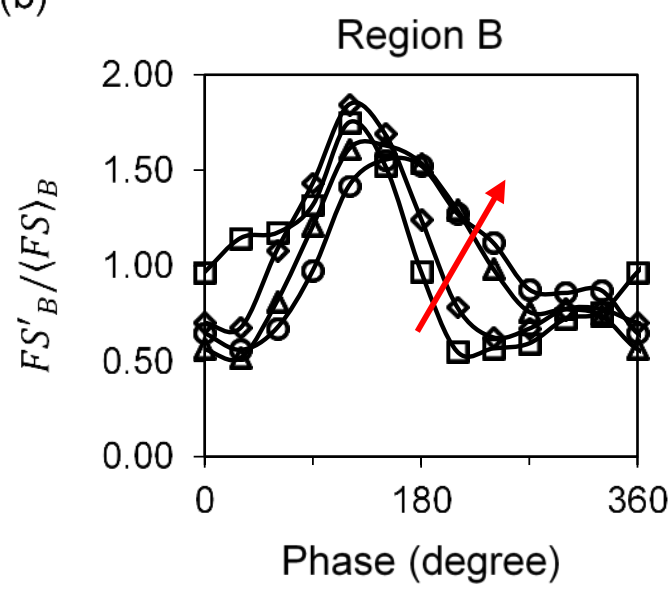

(c)

Region C

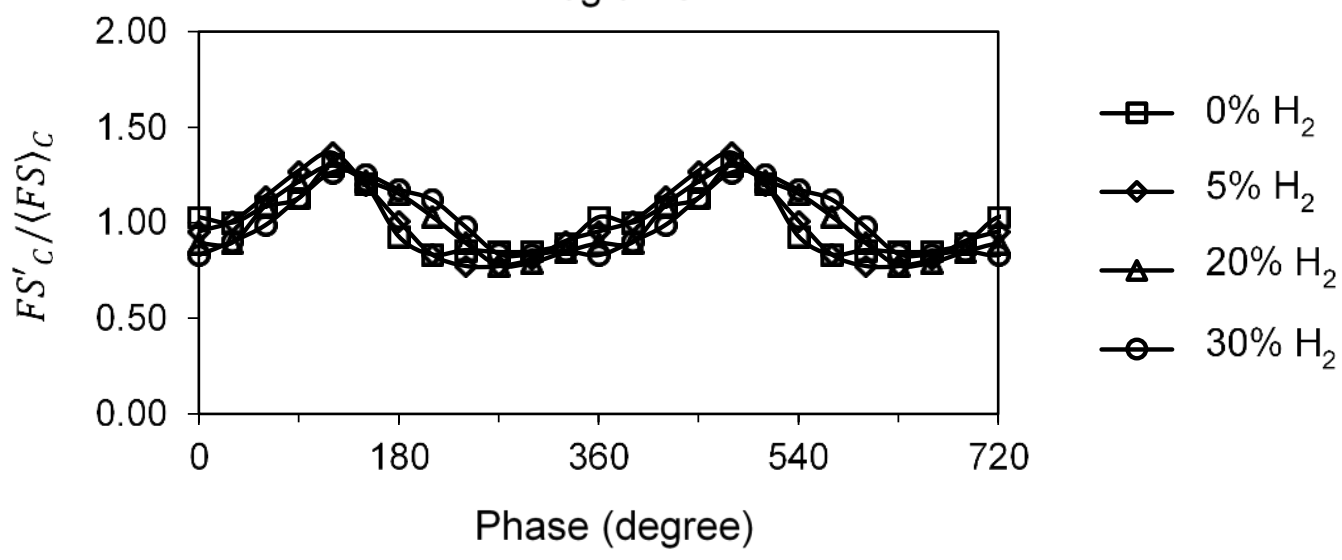

Figure 8: Cyclic variation of the normalised flame surface area, $F S^{\prime} /\langle F S\rangle$, for the regions (a) A, 2.5 $15 \mathrm{~mm}$, (b) B, $25-40 \mathrm{~mm}$, and (c) C, $2.5-40 \mathrm{~mm}$, for imperfectly premixed ethylene flames with increasing quantities of hydrogen addition under forcing conditions, $f=255 \mathrm{~Hz}$, and $u^{\prime} \mid\langle U\rangle=0.4$

Figure 7 shows the effect of $\mathrm{H}_{2}$ addition on the global heat release fluctuation, $Q^{\prime}(f) /\langle Q\rangle$, and on the magnitude of the flame describing function, $F D F$ (evaluated from $\mathrm{OH}^{*}$ chemiluminescence), for forced imperfectly premixed ethylene flames. It can be seen in this figure that at the lowest forcing frequency of $30 \mathrm{~Hz}$, the local addition of $\mathrm{H}_{2}$ of $5 \%$ resulted in a slight reduction in the heat release fluctuation. Further increase in $\mathrm{H}_{2}$ addition levels caused a minimal change in the response. However, at the higher forcing frequencies of $255 \mathrm{~Hz}$ and $315 \mathrm{~Hz}$, there was noticeable reduction in the heat release fluctuation with the addition of $\mathrm{H}_{2}$. The magnitude of the $F D F$ (Fig. 7) also reduced with $\mathrm{H}_{2}$ addition, however, the change was negligible beyond $\mathrm{H}_{2}$ addition of $20 \%$.

Figure 8 shows the cyclic variation in the normalised flame surface area, $F S^{\prime} /\langle F S\rangle$, for the three regions of the flame surface (as described in Section 3.2) for the same ethylene flames, at a forcing frequency, $f$, of $255 \mathrm{~Hz}$ and $u^{\prime} /\langle U\rangle=0.4$. The effect of $\mathrm{H}_{2}$ on the flame surface area $(F S)$ is most apparent from phase angles $180^{\circ}$ to $240^{\circ}$ in region $\mathrm{A}$, and from $0^{\circ}$ to $240^{\circ}$ in region $\mathrm{B}$. In region $\mathrm{C}$, which represents the overall flame, the $F S$ value changed significantly from $150^{\circ}$ to $240^{\circ}$ as the percentage $\mathrm{H}_{2}$ was 
increased. The percentage contribution of region $\mathrm{A}$ to region $\mathrm{C}$ was $16-17 \%$, while that of region $\mathrm{B}$ to region $\mathrm{C}$ ranged between $29-35 \%$. Hence, based on these contribution values and the overall flame surface fluctuation, it can be concluded that the most significant change in the FS occurred in region B. These changes will be further discussed in detail when evaluating the flame front images in Fig. 11.
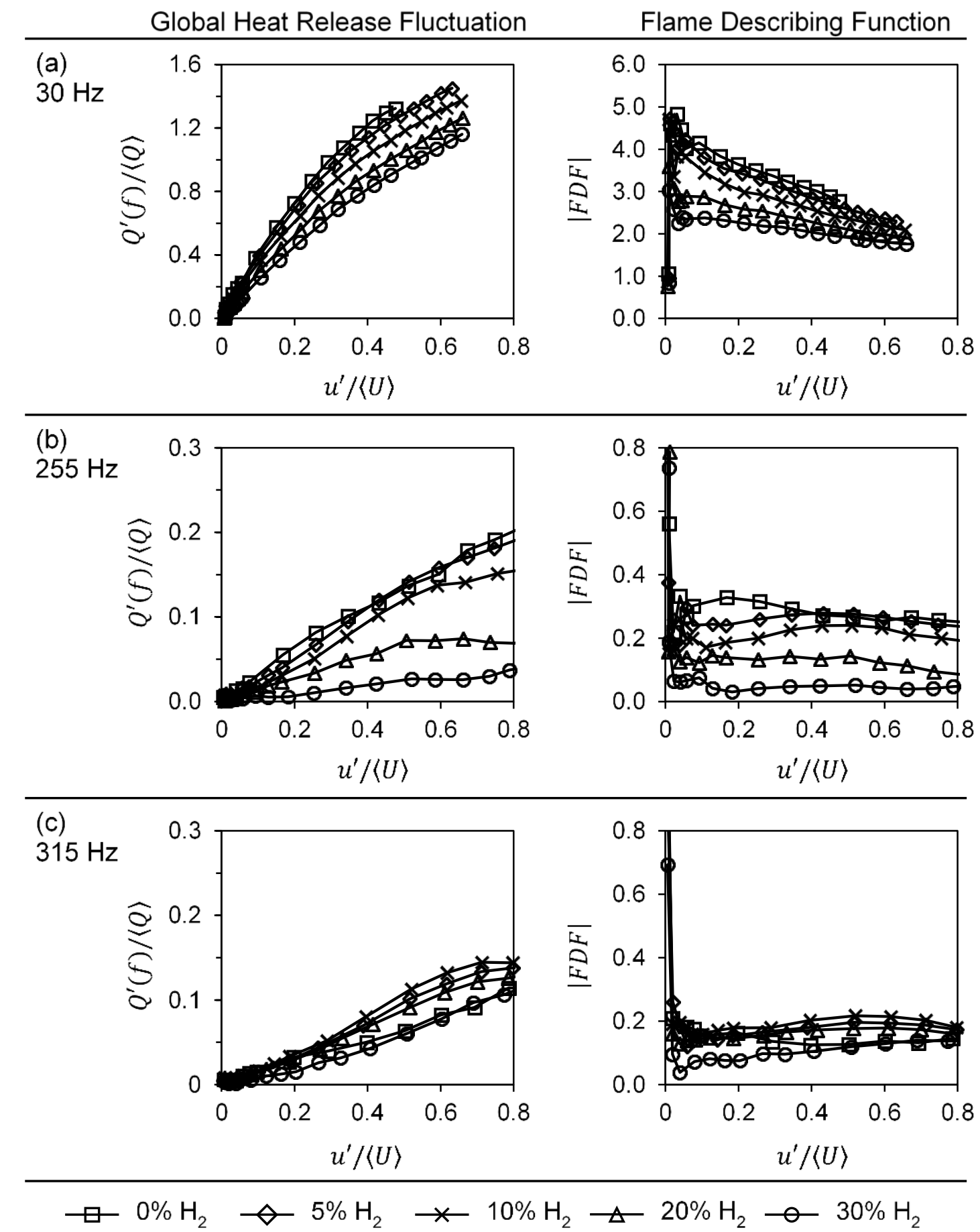

Figure 9: Dependence of the global heat release fluctuation and the magnitude of the flame describing function evaluated from $\mathrm{OH}^{\star}$ chemiluminescence of imperfectly premixed methane flames with local addition of hydrogen on velocity fluctuations, at forcing frequencies of (a) $30 \mathrm{~Hz}$, (b) $255 \mathrm{~Hz}$, and (c) $315 \mathrm{~Hz}$. 
(a)

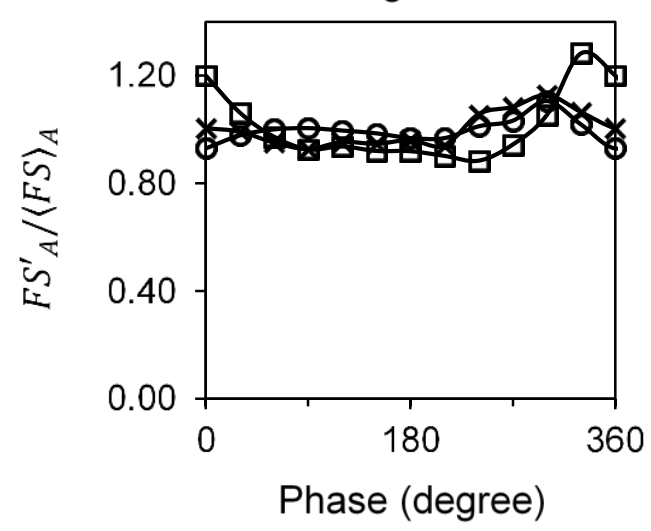

(b)

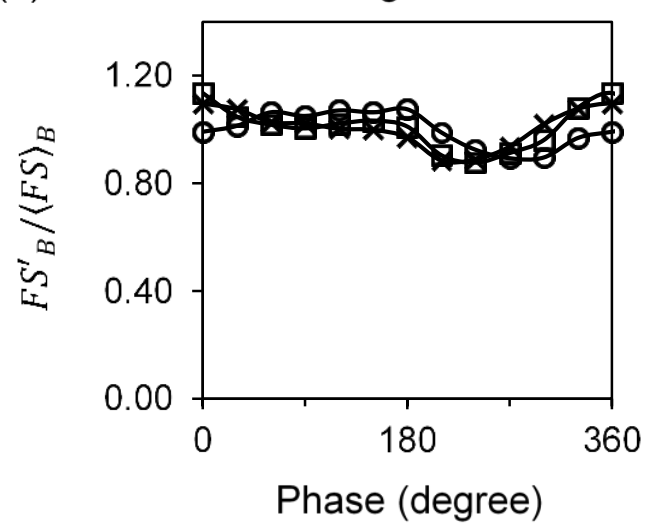

(c)

Region C

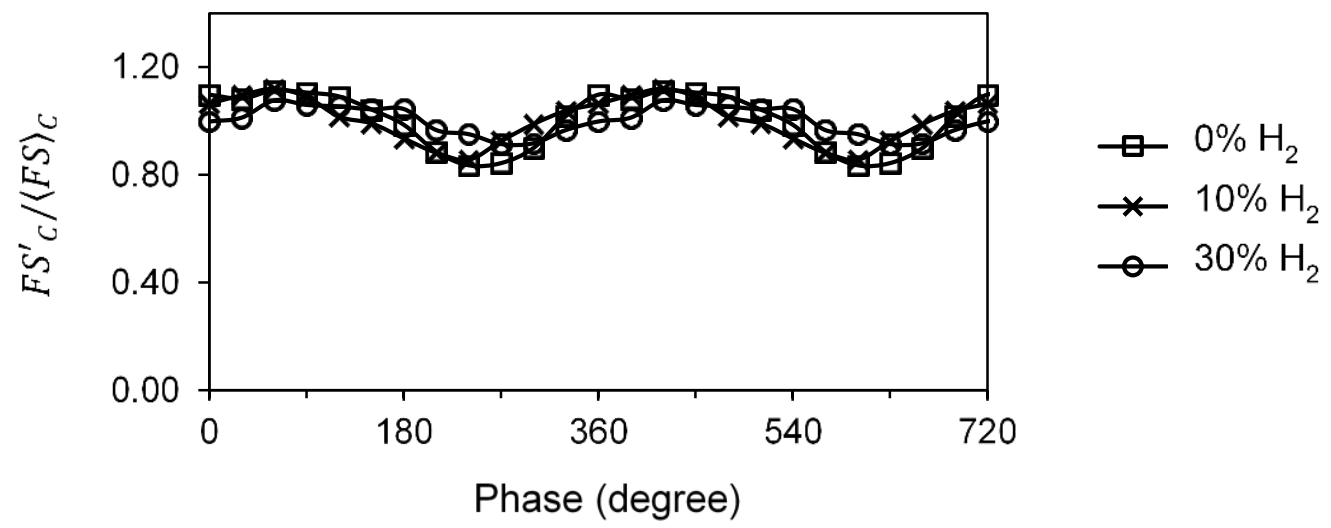

Figure 10: Cyclic variation of the normalised flame surface area, $F S^{\prime \prime}\langle F S\rangle$, for the regions (a) A, 2.5 $15 \mathrm{~mm}$, (b) B, $25-40 \mathrm{~mm}$, and (c) C, $2.5-40 \mathrm{~mm}$, for imperfectly premixed methane flames with increasing quantities of hydrogen addition under forcing conditions, $f=255 \mathrm{~Hz}$, and $u^{\prime} \mid\langle U\rangle=0.4$

Figure 9 shows the effect of $\mathrm{H}_{2}$ addition on the global heat release fluctuation, $Q^{\prime}(f) /\langle Q\rangle$, and on the magnitude of the flame describing function, $F D F$ (evaluated from $\mathrm{OH}^{*}$ chemiluminescence), for forced imperfectly premixed methane flames. From Fig. 9 it can be observed that at the lowest forcing frequency of $30 \mathrm{~Hz}$, there was an incremental reduction in the heat release fluctuation with increasing $\mathrm{H}_{2}$ addition. However, at $255 \mathrm{~Hz}$ forcing frequency, a significant reduction in the fluctuation was observed at all $\mathrm{H}_{2}$ addition levels, particularly at $20 \%$ and $30 \% \mathrm{H}_{2}$ addition. When the forcing frequency was increased to $355 \mathrm{~Hz}$, the effect of $\mathrm{H}_{2}$ on the heat release fluctuation reversed, that is, the fluctuation increased with increasing $\mathrm{H}_{2}$ addition. The magnitude of the $F D F$ was also observed to reduce with $\mathrm{H}_{2}$ addition, with the greatest change observed at $255 \mathrm{~Hz}$ (Fig. 9b).

Figure 10 shows the cyclic variation in the normalised flame surface area, $F S^{\prime} /\langle F S\rangle$, for the three regions of the flame surface (as described in Section 3.2) for the same methane flames, at a forcing frequency, $f$, of $255 \mathrm{~Hz}$ and $u^{\prime} /\langle U\rangle=0.4$. In region $\mathrm{A}$, an increase in $F S$ values was observed between phase angles $150^{\circ}$ and $240^{\circ}$ with $\mathrm{H}_{2}$ addition, however, the $F S$ reduced for phase angles beyond $240^{\circ}$. In region $\mathrm{B}$, only subtle changes in the peak-to-peak variation were observed. However, in region $\mathrm{C}$ there was a 
noticeable reduction in the peak-to-peak magnitude of the normalised flame surface fluctuation with $\mathrm{H}_{2}$ addition, with the highest reduction observed at $30 \% \mathrm{H}_{2}$ addition. This reduction could potentially explain the reduction in the heat release fluctuation with $\mathrm{H}_{2}$ addition at $255 \mathrm{~Hz}$ (Fig. 9b).

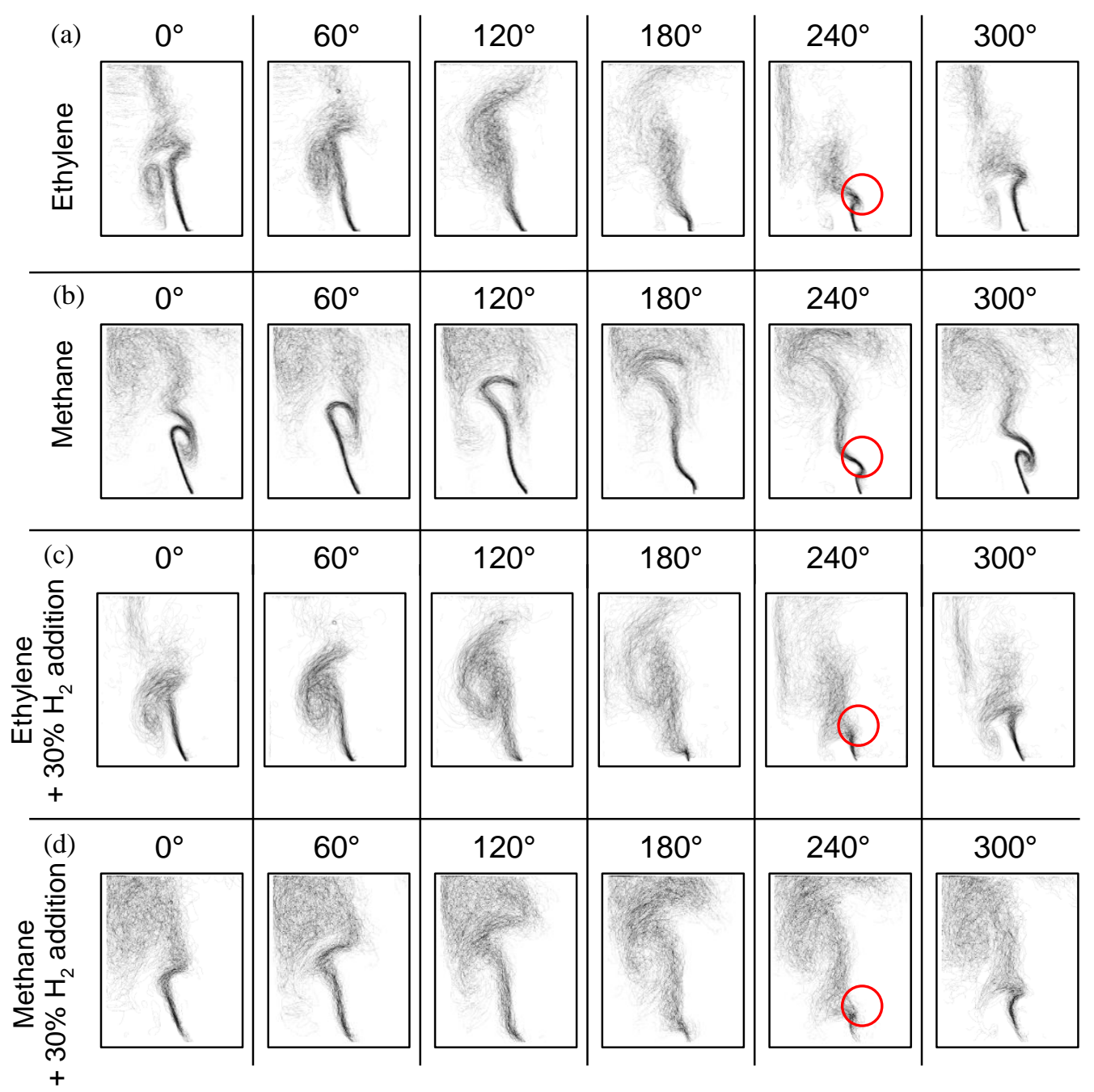

Figure 11: Phase-locked averaged flame front images (in steps of $60^{\circ}$ ), for imperfectly premixed ethylene and methane flames, with $0 \%$ and $30 \% \mathrm{H}_{2}$ addition, under forcing conditions, $f=255 \mathrm{~Hz}$, and $u^{\prime} \mid\langle U\rangle=0.4$

Figure 11 shows the phase locked averaged flame front images for both imperfectly premixed ethylene and methane flames, with $0 \%$ and $30 \% \mathrm{H}_{2}$ addition. The images shown are at a forcing frequency, $f$, of $255 \mathrm{~Hz}$ and amplitude, $u^{\prime} /\langle U\rangle$, of 0.4. First considering the ethylene flames, it can be observed from Fig. 11a that a flame surface started to roll-up nearer to the base of the flame from $240^{\circ}$ (annotated by the red circle). Flame roll-up occurs when the inner and outer shear layer simultaneously curl to create a counter rotating vortex pair. However, the local addition of $30 \% \mathrm{H}_{2}$ significantly reduced the size of the flame roll-up (Fig. 11b). The reason for this change in the shape of the flame front could be attributed to the increase in local flame speeds due to the addition of $\mathrm{H}_{2}$. The increase in flame speeds increased the rate of consumption of the fuel-air mixture, hence resulting in a reduction in flame area due to roll up. Further downstream (away from the base of the flame) the flame brush can be observed to increase 
with the addition of $\mathrm{H}_{2}$. With reference to Fig. 8, it can now be deduced that the reduction in $F S$ in region A (denoted by the blue arrow) was due to the decrease in the size of the flame roll-up nearer to the base of the flame, while the change in region B (denoted by the red arrow) was due to the reduction in the loss of flame surface.

Similar observations can be made when analysing the effect of $\mathrm{H}_{2}$ addition on methane flames (Fig. 11b and 11d). A distinctive roll-up of the flame surface can be seen to occur from the beginning (phase angle $0^{\circ}$ ) for the methane only flame (Fig. 11b). The size of this roll-up is seen to increase as it moves further downstream in the flame before eventually collapsing. A new vortex is then observed to form closer to the burner surface (phase angle $240^{\circ}$, annotated by red circle). The addition of $30 \% \mathrm{H}_{2}$ (Fig. 11d) reduces the flame roll up significantly across all phase angles. As discussed earlier, this could be attributed to the addition of $\mathrm{H}_{2}$ resulting in faster consumption of the unburned mixture. Furthermore, the flame brush thickness increases considerably close to the base of the flame. This reduction in flame surface area due to the reduction in the size of the roll up can explain the changes observed in Fig. 10 with the addition of $\mathrm{H}_{2}$. 

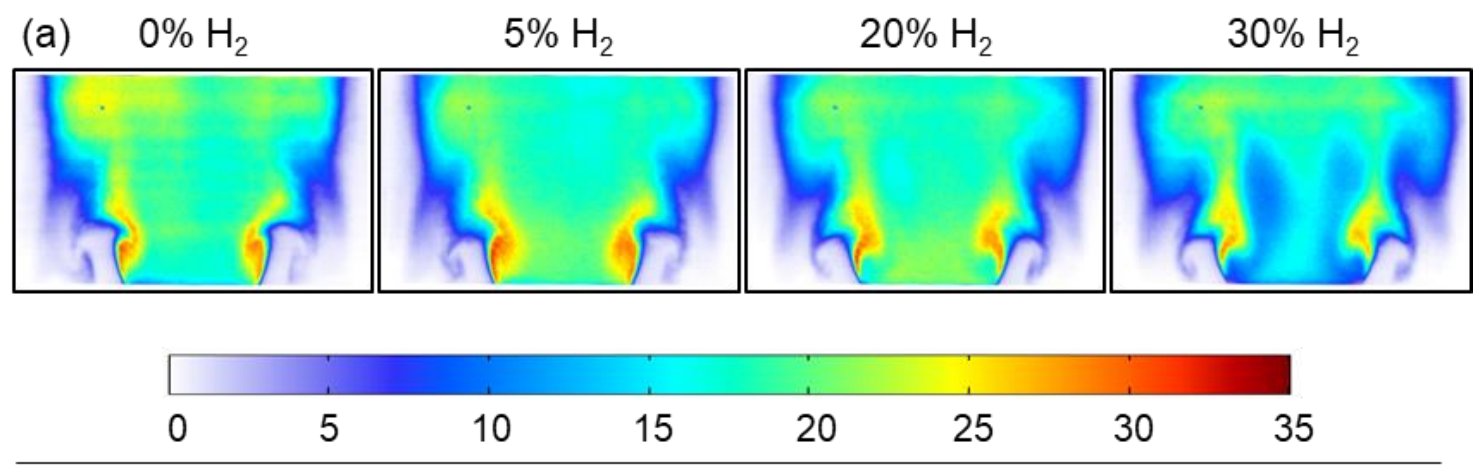

(b)

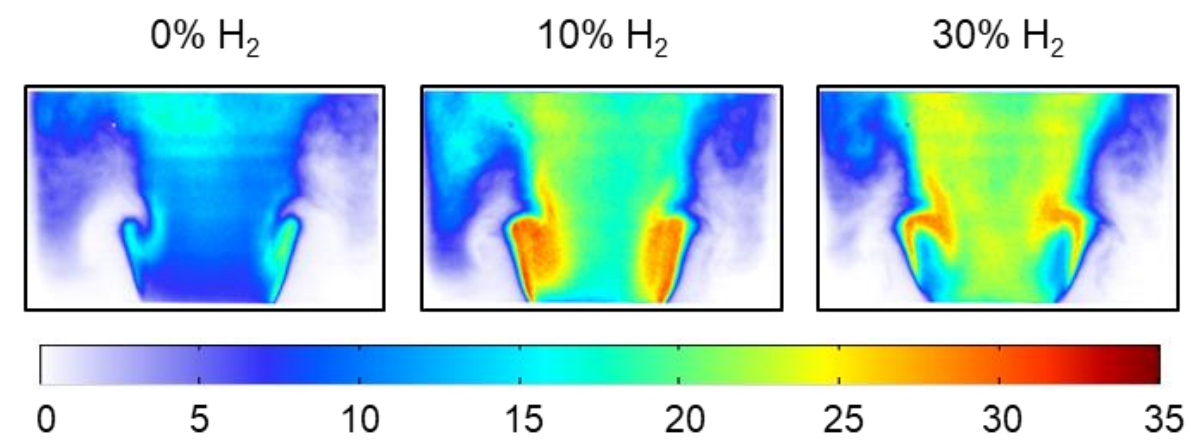

Figure 12: Averaged OH PLIF images of forced imperfectly premixed flames with varying quantities of hydrogen addition at $f=255 \mathrm{~Hz}$, and $u^{\prime} \mid\langle U\rangle=0.4$, phase-locked at (a) $270^{\circ}$ for ethylene flames and (b) $0^{\circ}$ for methane flames.

Figure 12 show the averaged OH PLIF images for both imperfectly premixed ethylene and methane flames, forced at frequency, $f$, of $255 \mathrm{~Hz}$ and amplitude, $u^{\prime} /\langle U\rangle$, of 0.4 . Pure ethylene $\left(0 \% \mathrm{H}_{2}\right)$ flames were observed to have a greater OH PLIF signal intensity as compared to methane only flames, attributable to a higher concentration of $\mathrm{OH}$ radicals and higher flame temperatures. As seen in the flame front images previously (Fig. 11), it can also be observed here, for both ethylene and methane flames, that the addition of $\mathrm{H}_{2}$ reduced the size of the flame roll-up. Comparing the $\mathrm{OH}$ signal intensity for the ethylene and methane flames, it can be observed that the ethylene flames had a higher $\mathrm{OH}$ signal, which could be either due to the presence of a higher concentration of $\mathrm{OH}$ radicals, or increased flame temperature. It is interesting to note that in the case of the ethylene flames, the $\mathrm{OH}$ signal intensity at the centre recirculation zone reduced with increasing $\mathrm{H}_{2}$ addition. However, this was not observed for the methane flames, where the $\mathrm{OH}$ signal intensity was observed to increase with increasing $\mathrm{H}_{2}$ addition (Fig. 12b). 


\section{Conclusion}

The work carried out in this study focused on the effect of local addition of $\mathrm{H}_{2}$ to imperfectly premixed ethylene and imperfectly premixed methane flames. The flames were studied under both unforced and forced conditions. Ethylene flames were observed to have a greater OH PLIF signal intensity as compared to methane flames, attributable to a higher concentration of $\mathrm{OH}$ radicals and higher flame temperatures. The addition of $\mathrm{H}_{2}$ increased the $\mathrm{OH}$ and $\mathrm{H}$ PLIF signal near the inner shear layer, for both ethylene and methane flames. The flame front images showed that that a $30 \% \mathrm{H}_{2}$ addition caused the flame height to reduce and flames to lift slightly from the base, for both ethylene and methane. A substantial increase in NOx exhaust emissions was observed with the addition of $\mathrm{H}_{2}$ for both ethylene and methane flames, however, the absolute NOx concentrations were considerably higher for the ethylene flames (due to higher flame temperatures). Comparing the dynamic response (that is, forced flame) results of both the base fuel types, it was observed that the global heat release fluctuation was higher in the case of ethylene at forcing frequencies $255 \mathrm{~Hz}$ and $315 \mathrm{~Hz}$. The addition of $\mathrm{H}_{2}$ generally resulted in the reduction in heat release oscillations for both ethylene and methane flames. The only exception to this was observed for methane flames at a forcing frequency of $315 \mathrm{~Hz}$, where the fluctuations increased with increasing $\mathrm{H}_{2}$. Considering the flame surface area, it was observed that the addition of $\mathrm{H}_{2}$ reduced the initial flame front roll-up for both ethylene and methane flames. However, this reduction was larger for methane flames as compared to ethylene, suggesting that $\mathrm{H}_{2}$ had a greater effect on methane flames, as compared to ethylene.

The observations from this study indicate that the effectiveness of $\mathrm{H}_{2}$ addition in modifying the heat release in hydrocarbon flames varies based on the choice of the primary fuel and the excitation parameters. However, irrespective of fuel choice, local addition of $\mathrm{H}_{2}$ reduces flame dynamics and this approach has the potential to be used for the control of combustion instabilities.

\section{Acknowledgements}

The authors would like to acknowledge EPSRC (EP/P003036/1 and EP/G063788/1) for their support towards this work. The authors would like to thank Dr. Paul Hellier for his help with the emissions measurements. 


\section{Nomenclature}

$\begin{array}{ll}\mathrm{CH}_{4} & \text { Methane } \\ \mathrm{C}_{2} \mathrm{H}_{4} & \text { Ethylene } \\ \mathrm{H}_{2} & \text { Hydrogen } \\ \mathrm{NOx} & \text { Nitrogen oxides } \\ F D F & \text { Flame Describing Function } \\ \mathrm{OH}^{*} & \text { Hydroxyl radical } \\ \mathrm{PMT} & \text { Photo Multiplier Tube } \\ \mathrm{PLIF} & \text { Planar Laser Induced Fluorescence } \\ \Phi_{\text {Global }} & \text { Global equivalence ratio } \\ p & \text { Pressure } \\ u, U & \text { Velocity } \\ Q & \text { Heat release } \\ F S & \text { Flame surface/flame length }\end{array}$

\section{References}

[1] Zheng L, Cronly J, Ubogu E, Ahmed I, Zhang Y, Khandelwal B. Experimental investigation on alternative fuel combustion performance using a gas turbine combustor. Appl Energy 2019;238:1530-42. doi:10.1016/j.apenergy.2019.01.175.

[2] Kurata O, Iki N, Inoue T, Matsunuma T, Tsujimura T, Furutani H, et al. Development of a wide range-operable, rich-lean low-NOx combustor for NH3 fuel gas-turbine power generation. Proc Combust Inst 2019;37:4587-95. doi:10.1016/j.proci.2018.09.012.

[3] Ruan C, Chen F, Cai W, Qian Y, Yu L, Lu X. Principles of non-intrusive diagnostic techniques and their applications for fundamental studies of combustion instabilities in gas turbine combustors: A brief review. Aerosp Sci Technol 2019;84:585-603. doi:10.1016/j.ast.2018.10.002.

[4] Rajpara P, Shah R, Banerjee J. Effect of hydrogen addition on combustion and emission characteristics of methane fuelled upward swirl can combustor. Int J Hydrogen Energy 2018;43:17505-19. doi:10.1016/j.ijhydene.2018.07.111. 
[5] Reyes M, Tinaut FV, Giménez B, Pastor J V. Effect of hydrogen addition on the $\mathrm{OH}^{*}$ and $\mathrm{CH}^{*}$ chemiluminescence emissions of premixed combustion of methane-air mixtures. Int J Hydrogen Energy 2018;43:19778-91. doi:10.1016/j.ijhydene.2018.09.005.

[6] Candel S. Combustion dynamics and control: Progress and challenges. Proc Combust Inst 2002;29:1-28. doi:10.1016/S1540-7489(02)80007-4.

[7] Dowling AP, Morgans AS. Feedback control of combustion oscillations. Annu Rev Fluid Mech 2005;37:151-82. doi:10.1146/annurev.fluid.36.050802.122038.

[8] Lieuwen TC, Yang V. Combustion Instabilities In Gas Turbine Engines. Reston,VA: American Institute of Aeronautics and Astronautics; 2006. doi:10.2514/4.866807.

[9] Merk M, Gaudron R, Silva C, Gatti M, Mirat C, Schuller T, et al. Prediction of combustion noise of an enclosed flame by simultaneous identification of noise source and flame dynamics. Proc Combust Inst 2018.

[10] Swaminathan N, Xu N, Dowling AP, Balachandran R. Heat release rate correlation and combustion noise in premixed flames. J Fluid Mech 2011;681:80-115. doi:10.1017/jfm.2011.232.

[11] Blomshield F. Historical perspective of combustion instability in motors - Case studies. 37th Jt. Propuls. Conf. Exhib., Reston, Virigina: American Institute of Aeronautics and Astronautics; 2001. doi:10.2514/6.2001-3875.

[12] Putnam AA. Combustion-driven oscillations in industry. New York: American Elsevier Pub. Co; 1971.

[13] Smith T, Emerson B, Proscia W, Lieuwen T. Role of induced axial acoustics in transverse acoustic flame response. Combust Flame 2018.

[14] Kim H, Arghode V, Gupta A. Flame characteristics of hydrogen-enriched methane-air premixed swirling flames. Int J Hydrogen Energy 2009;34:1063-73. doi:10.1016/j.ijhydene.2008.10.035.

[15] Schadow KC, Gutmark E. Combustion instability related to vortex shedding in dump combustors and their passive control. Prog Energy Combust Sci 1992;18:117-32. doi:10.1016/0360-1285(92)90020-2.

[16] Tran N, Ducruix S, Schuller T. Damping combustion instabilities with perforates at the premixer inlet of a swirled burner. Proc Combust Inst 2009;32:2917-24. doi:10.1016/j.proci.2008.06.123.

[17] Emiris I, Whitelaw JH. Control of combustion oscillations. Combust Sci Technol 
2003;175:157-84. doi:10.1080/00102200302363.

[18] Nair S, Lieuwen T. Acoustic Detection of Imminent Blowout in Pilot and Swirl Stabilized Combustors. Vol. 2 Turbo Expo 2003, ASME; 2003, p. 55-65. doi:10.1115/GT2003-38074.

[19] Bradley D, Gaskell P., Gu XJ, Lawes M, Scott MJ. Premixed turbulent flame instability and NO formation in a lean-burn swirl burner. Combust Flame 1998;115:515-38. doi:10.1016/S00102180(98)00024-8.

[20] Albrecht P, Bade S, Lacarelle A, Paschereit CO, Gutmark E. Instability Control by Premixed Pilot Flames. J Eng Gas Turbines Power 2010;132:041501. doi:10.1115/1.3019293.

[21] Mansour MS, Chen Y-C, Peters N. Highly strained turbulent rich methane flames stabilized by hot combustion products. Combust Flame 1999;116:136-53. doi:10.1016/S00102180(98)00029-7.

[22] Sattinger SS, Neumeier Y, Nabi A, Zinn BT, Amos DJ, Darling DD. Sub-Scale Demonstration of the Active Feedback Control of Gas-Turbine Combustion Instabilities. J Eng Gas Turbines Power 2000;122:262. doi:10.1115/1.483204.

[23] Galizzi C, Escudié D. Experimental analysis of an oblique turbulent flame front propagating in a stratified flow. Combust Flame 2010;157:2277-85. doi:10.1016/j.combustflame.2010.07.008.

[24] Kim KT, Hochgreb S. The nonlinear heat release response of stratified lean-premixed flames to acoustic velocity oscillations. Combust Flame 2011;158:2482-99. doi:10.1016/j.combustflame.2011.05.016.

[25] Balusamy S, Li LKB, Han Z, Hochgreb S. Extracting flame describing functions in the presence of self-excited thermoacoustic oscillations. Proc Combust Inst 2017;36:3851-61.

[26] Robin V, Mura A, Champion M, Degardin O, Renou B, Boukhalfa M. Experimental and numerical analysis of stratified turbulent V-shaped flames. Combust Flame 2008;153:288-315. doi:10.1016/j.combustflame.2007.10.008.

[27] Marzouk YM, Ghoniem AF, Najm HN. Dynamic response of strained premixed flames to equivalence ratio gradients. Proc Combust Inst 2000;28:1859-66. doi:10.1016/S00820784(00)80589-5.

[28] Nogenmyr K-J, Petersson P, Bai XS, Fureby C, Collin R, Lantz A, et al. Structure and stabilization mechanism of a stratified premixed low swirl flame. Proc Combust Inst 2011;33:1567-74. doi:10.1016/j.proci.2010.06.011. 
[29] Schefer RW, Wicksall DM, Agrawal AK. Combustion of hydrogen-enriched methane in a lean premixed swirl-stabilized burner. Proc Combust Inst 2002;29:843-51. doi:10.1016/S15407489(02)80108-0.

[30] Kim H, Arghode V, Linck M, Gupta A. Hydrogen addition effects in a confined swirl-stabilized methane-air flame. Int J Hydrogen Energy 2009;34:1054-62. doi:10.1016/j.ijhydene.2008.10.034.

[31] Mardani A, Tabejamaat S. Effect of hydrogen on hydrogen-methane turbulent non-premixed flame under MILD condition. Int J Hydrogen Energy 2010;35:11324-31. doi:10.1016/j.ijhydene.2010.06.064.

[32] Cozzi F, Coghe A. Behavior of hydrogen-enriched non-premixed swirled natural gas flames. Int J Hydrogen Energy 2006;31:669-77. doi:10.1016/j.ijhydene.2005.05.013.

[33] Mandilas C, Ormsby MP, Sheppard CGW, Woolley R. Effects of hydrogen addition on laminar and turbulent premixed methane and iso-octane-air flames. Proc Combust Inst 2007;31:144350. doi:10.1016/j.proci.2006.07.157.

[34] Day MS, Gao X, Bell JB. Properties of lean turbulent methane-air flames with significant hydrogen addition. Proc Combust Inst 2011;33:1601-8. doi:10.1016/j.proci.2010.05.099.

[35] Barbosa S, de La Cruz Garcia M, Ducruix S, Labegorre B, Lacas F. Control of combustion instabilities by local injection of hydrogen. Proc Combust Inst 2007;31:3207-14. doi:10.1016/j.proci.2006.07.085.

[36] El-Ghafour SAA, El-dein AHE, Aref AAR. Combustion characteristics of natural gas-hydrogen hybrid fuel turbulent diffusion flame. Int J Hydrogen Energy 2010;35:2556-65. doi:10.1016/j.ijhydene.2009.12.049.

[37] Jiménez C, Quinard J, Graña-Otero J, Schmidt H, Searby G. Unsteady response of hydrogen and methane flames to pressure waves. Combust Flame 2012;159:1894-908. doi:10.1016/j.combustflame.2012.01.017.

[38] Wicksall D, Agrawal A. Acoustics measurements in a lean premixed combustor operated on hydrogen/hydrocarbon fuel mixtures. Int J Hydrogen Energy 2007;32:1103-12. doi:10.1016/j.ijhydene.2006.07.008.

[39] Chen Z. Effects of hydrogen addition on the propagation of spherical methane/air flames: A computational study. Int J Hydrogen Energy 2009;34:6558-67. doi:10.1016/j.ijhydene.2009.06.001. 
[40] Choudhuri AR, Gollahalli SR. Characteristics of hydrogen-hydrocarbon composite fuel turbulent jet flames. Int $\mathrm{J}$ Hydrogen Energy 2003;28:445-54. doi:10.1016/S03603199(02)00063-0.

[41] Ilbas M, Yilmaz I, Kaplan Y. Investigations of hydrogen and hydrogen-hydrocarbon composite fuel combustion and emission characteristics in a model combustor. Int J Hydrogen Energy 2005;30:1139-47. doi:10.1016/j.ijhydene.2004.10.016.

[42] Guo H, Tayebi B, Galizzi C, Escudié D. Burning rates and surface characteristics of hydrogenenriched turbulent lean premixed methane-air flames. Int J Hydrogen Energy 2010;35:113428. doi:10.1016/j.ijhydene.2010.07.066.

[43] Dahl G, Suttrop F. Engine control and low-NOx combustion for hydrogen fuelled aircraft gas turbines. Int J Hydrogen Energy 1998;23:695-704. doi:10.1016/S0360-3199(97)00115-8.

[44] Balachandran R, Ayoola B, Kaminski C, Dowling A, Mastorakos E. Experimental investigation of the nonlinear response of turbulent premixed flames to imposed inlet velocity oscillations. Combust Flame 2005;143:37-55. doi:10.1016/j.combustflame.2005.04.009.

[45] Lieuwen T. Nonlinear kinematic response of premixed flames to harmonic velocity disturbances. Proc Combust Inst 2005;30:1725-32. doi:10.1016/j.proci.2004.07.020.

[46] Dowling AP. A kinematic model of a ducted flame. J Fluid Mech 1999;394:S0022112099005686. doi:10.1017/S0022112099005686.

[47] Zhang Z, Zhao D, Dobriyal R, Zheng Y, Yang W. Theoretical and experimental investigation of thermoacoustics transfer function. Appl Energy 2015;154:131-42. doi:10.1016/j.apenergy.2015.04.026.

[48] Kypraiou AM, Giusti A, Allison PM, Mastorakos E. Dynamics of acoustically forced nonpremixed flames close to blow-off. Exp Therm Fluid Sci 2018;95:81-7. doi:10.1016/j.expthermflusci.2018.01.036.

[49] Balusamy S, Li LKB, Han Z, Juniper MP, Hochgreb S. Nonlinear dynamics of a self-excited thermoacoustic system subjected to acoustic forcing. Proc Combust Inst 2015;35:3229-36. doi:10.1016/j.proci.2014.05.029.

[50] Saurabh A, Paschereit CO. Dynamics of premixed swirl flames under the influence of transverse acoustic fluctuations. Combust Flame 2017;182:298-312. doi:10.1016/j.combustflame.2017.04.014.

[51] Kim T, Ahn M, Hwang J, Kim S, Yoon Y. The experimental investigation on the response of 
the Burke-Schumann flame to acoustic excitation. Proc Combust Inst 2017;36:1629-36. doi:10.1016/j.proci.2016.06.116.

[52] Lee JG, Kim K, Santavicca DA. Measurement of equivalence ratio fluctuation and its effect on heat release during unstable combustion. Proc Combust Inst 2000;28:415-21. doi:10.1016/S0082-0784(00)80238-6.

[53] Srinivasan S, Ranjan R, Menon S. Flame Dynamics During Combustion Instability in a HighPressure, Shear-Coaxial Injector Combustor. Flow, Turbul Combust 2015;94:237-62. doi:10.1007/s10494-014-9569-x.

[54] Semlitsch B, Orchini A, Dowling AP, Juniper MP. G -equation modelling of thermoacoustic oscillations of partially premixed flames. Int J Spray Combust Dyn 2017;9:260-76. doi:10.1177/1756827717711405.

[55] COSILAB. The combustion simulation laboratory, version 2.1. Rotexo GmbH \& Co. 2017.

[56] Ayoola BO, Balachandran R, Frank JH, Mastorakos E, Kaminski CF. Spatially resolved heat release rate measurements in turbulent premixed flames. Combust Flame 2006;144:1-16. doi:10.1016/j.combustflame.2005.06.005.

[57] Langhorne PJ. Reheat buzz: an acoustically coupled combustion instability. Part 1. Experiment. J Fluid Mech 1988;193:417. doi:10.1017/S0022112088002204.

[58] Lawn CJ, Evesque S, Polifke W. A MODEL FOR THE THERMOACOUSTIC RESPONSE OF A PREMIXED SWIRL BURNER, PART I: ACOUSTIC ASPECTS. Combust Sci Technol 2004;176:1331-58. doi:10.1080/00102200490461605.

[59] Lawn CJ. Distributions of instantaneous heat release by the cross-correlation of chemiluminescent emissions. Combust Flame 2000;123:227-40. doi:10.1016/S00102180(00)00129-2.

[60] Hemchandra S, Peters N, Lieuwen T. Heat release response of acoustically forced turbulent premixed flames-role of kinematic restoration. Proc Combust Inst 2011;33:1609-17. doi:10.1016/j.proci.2010.06.115.

[61] Kim D, Park SW. Effects of hydrogen addition on flame structure and forced flame response to velocity modulation in a turbulent lean premixed combustor. Fuel 2010;89:3475-81. doi:10.1016/j.fuel.2010.06.021.

[62] Otsu N. A Threshold Selection Method from Gray-Level Histograms. IEEE Trans Syst Man Cybern 1979;9:62-6. doi:10.1109/TSMC.1979.4310076. 
[63] Bowman CT. Kinetics of nitric oxide formation incombustion processes. Symp Combust 1973;14:729-38. doi:10.1016/S0082-0784(73)80068-2.

[64] Miller JA, Bowman CTC. Mechanism and modeling of nitrogen chemistry in combustion. Prog Energy Combust Sci 1989;15:287-338. doi:10.1016/0360-1285(89)90017-8. 